\title{
Update on Memory Systems and Processes
}

\author{
Lynn Nadel ${ }^{\star, 1}$ and Oliver Hardt ${ }^{2}$ \\ ${ }^{1}$ Department of Psychology, University of Arizona, Tucson, AZ, USA; ${ }^{2}$ Department of Psychology, McGill University, \\ Montreal, QC, Canada
}

\begin{abstract}
Ideas about how the brain organizes learning and memory have been evolving in recent years, with potentially important ramifications. We review traditional thinking about learning and memory and consider more closely emerging trends from both human and animal research that could lead to profound shifts in how we understand the neural basis of memory. Neuropsychopharmacology Reviews (2011) 36, 251-273; doi: I0. I038/npp.20 I0.169; published online 22 September 2010
\end{abstract}

Keywords: learning and memory; cognition; psychiatry and behavioral sciences; behavioral science; memory systems

\section{INTRODUCTION}

Ideas about how the brain organizes learning and memory have been evolving in recent years, with potentially important ramifications for psychiatry. Conditions such as schizophrenia, depression, and various anxiety disorders all have been shown to reflect, among other things, impairments in how individuals use, or misuse, previous experience (eg, Barch, 2006; Kraus et al, 2009; Fletcher and Frith, 2009; Gibbs and Rude, 2004; Jacobs and Nadel, 1985). Our intention here is to review traditional thinking about learning and memory and then to consider more closely emerging trends that could lead to profound shifts in how we understand the neural basis of memory.

It is generally assumed that memory comes in many forms, that each form involves somewhat distinct neural systems, and that all forms involve cellular changes that take time to emerge and that then persist. We do not yet know exactly how to characterize these forms, which neural systems they engage, and what cellular and molecular processes underlie memory's persistence. Much progress has been made in recent years on each of these questions; we will discuss recent advances in understanding memory organization and stabilization processes primarily at the level of systems, with a focus on the kind of memory that in humans is expressed explicitly through words and actions. That is, we will focus on memories for episodes,

${ }^{*}$ Correspondence: Dr L Nadel, Department Of Psychology, University of Arizona, Tucson, AZ 85721, USA, Tel: +1520 248 0491, E-mail: nadel@u.arizona.edu

Received 25 May 2010; revised 11 August 2010; accepted 23 August 2010 and the things about the world we learn during such episodes. We will not be able to discuss at length other forms of memory, such as habit memory, emotional memory, and the memories formed during classical conditioning. A brief historical overview will introduce the basic issues.

\section{HISTORICAL OVERVIEW}

The modern era of memory research reflects three rather distinct traditions, one based in experimental analyses of learning and memory with roots back to antiquity, a second reflecting the investigation of brain-damaged individuals and in particular various amnesic patients, and the third reflecting the use of animal models to study memory phenomena at both the cellular and systems levels. Each of these traditions brought its own emphases to the field. Empirical studies of memory in the nineteenth century already established fundamental facts about learning rates and forgetting functions (eg, Ebbinghaus, 1885/1913; Ribot, 1881/1887). The idea that memories took time to 'consolidate' after learning was first mentioned in the context of list learning experiments (Müller and Pilzecker, 1900; Lechner et al, 1999), and the notion that there are multiple forms of memory was expressed by James (1890) and others, who distinguished between primary and secondary memory, what many now call short- (STM) and long-term memory (LTM). The behaviorist revolution, and its focus on observables, shifted attention from memory to the conditions that encouraged learning. Although memory is inferred, learning can be measured by latency, response rates, errors, and so on. Not all psychologists in the 
behaviorist era eschewed talk of memory: Bartlett (1932) in England made the important point that memory was 're-constructive' rather than merely repetitive. This perspective, largely ignored by behaviorism, has more recently had considerable impact.

Work with brain-damaged patients in the aftermath of Second World War re-emphasized the phenomenon of 'retrograde amnesia' (RA), the loss of access to memories formed before events causing brain injury (a phenomenon noted already by Ribot, 1881/1887). Russell and Nathan (1946) detailed the apparent loss, in such individuals, of memories going back months and even years. Discussions of RA focused on two possibilities: first, the problem might be one of retrieval; that is, memories are available, but inaccessible. Second, the problem might be one of storage: since memory consolidation requires time, memories that had not yet been consolidated at the time of brain injury could be lost forever.

The notion of memory consolidation, coupled with the distinction between STM and LTM, influenced Hebb's (1949) seminal cell assembly theory. Hebb suggested that initially a memory is represented in 'reverberating circuits', which serve as the neural basis of short-term storage. Sufficient 'reverberation' initiates structural changes that underlie consolidation and formation of permanent LTM. Before consolidation, interruption of reverberation would interfere with memory retrieval. At the conclusion of consolidation, interrupting reverberation would not lead to memory loss, as the pattern of activity representing a memory could now be reinstantiated by virtue of the structural change. Note that in this formulation, STM and LTM are represented within the same circuits. This notion of short-term memory has in recent years been subsumed under, or replaced by, the concept of 'working memory', but these putative processes are not the same (see Box 1).

The study of patients such as HM (eg, Scoville and Milner, 1957) showed that damage to the medial temporal lobe (MTL) (see Figure 1), and in particular the hippocampal formation, caused both anterograde amnesia and RA. Early work with HM, using coarse assessment tools, suggested that his STM was largely intact, and that his RA was limited to a few years at most. These findings were taken to support the view that the hippocampus played a crucial role in consolidating memories, perhaps by storing them for some period of time, but that after consolidation permanent memories were stored elsewhere.

Beginning in the late 1940s, animal models were used extensively to study memory. On the one hand, they were used to explore the process of memory consolidation: how long did it last, and what underlying neurobiological events are at its core? On the other hand, they were used to explore which neural systems were involved in memory storage and retrieval. It became clear fairly early that there would be no single answer to any of these questions. Consolidation times, processes, and systems vary as a function of the kind of learning involved.
Orbach et al (1960) attempted to replicate HM's amnestic syndrome with comparable lesions in primates, but their lesioned animals did not show memory deficits. This became easier to understand when it was shown that even amnesic patients with extensive hippocampal damage were able to acquire certain kinds of memories. Researchers in Canada (Milner, 1966; Corkin, 1968) and the UK (Warrington and Weiskrantz, 1968, 1970) independently showed this fact, but neither group immediately pursued the idea that there were separate neural systems responsible for different forms of learning. Instead, this idea emerged from other lines of research using animal models. Three separate and distinct proposals suggested the existence of multiple kinds of memory, one kind involving the hippocampus, but others not (Gaffan, 1974; Hirsh, 1974; Nadel and O'Keefe, 1974). Nadel and O'Keefe built on Tulving's (1972) distinction between episodic and semantic memory to help understand what amnesic patients could and could not learn and recall (Kinsbourne and Wood, 1975; O'Keefe and Nadel, 1978). They argued that the hippocampus represented spatial contexts, and as a result played a central role in episodic memory, which necessarily incorporates specific contextual information. In their view, the hippocampus was not critical to semantic memory, which represents information without necessary links to context. The question of how best to characterize the difference between hippocampal-dependent and hippocampal-independent memory has attracted considerable attention since the 1970s, as we discuss below. Any resolution of this question is complicated by the fact of RA, which in humans can last many years. The existence of RA suggests that memories can depend on the hippocampus at one point in time, but become independent of it later.

Both the extended time frame for memory consolidation and the apparent shift of memory from hippocampal dependence to independence pose significant explanatory challenges. With respect to the consolidation process itself, it is not clear how to think about cellular events and structural changes over extended time frames. It is now assumed that consolidation plays out at two different levels. On the one hand, there are short-term processes that engender the structural changes associated with permanent engrams. This has come to be called 'cellular consolidation'. On the other hand, there are much longer-term processes that reflect an apparent shift at the systems level: recent memories are said to require hippocampus, but after a longlasting 'systems consolidation' process more remote memories no longer depend on the hippocampus. However, as we see below, recent evidence suggests that when memories seemingly independent of the hippocampus are recalled they can once again, for a short time at least, become dependent on the hippocampus. These and other recent findings show that memory involves far more dynamic processes than previously acknowledged. What exactly happens during systems consolidation is one of the major issues we explore in this paper. Discussions of the neural substrates of memory and its consolidation are typically 


\section{Short-term memory (STM)}

In the first neurobiologically plausible model (Hebb, 1949), STM was defined as continuous reverberatory activity in cell assemblies (a set of interconnected neurons that encode a stimulus) — essentially, the neurons recurrently excite each other for some time after the original stimulation. Possibly due to depletion of neurotransmitter stores, at some point reverberation ceases, which marks the end of STM. In Hebb's model, long-term memory (LTM) can arise out of STM, if the reverberatory activity leads to structural changes in the synapses connecting the neurons of the cell assembly. The molecular mechanisms that lead to long-lasting changes in synaptic potentiation have been well characterized in recent years.

In the animal models used in behavioral neuroscience, STM is oftentimes defined in terms of the time required for post-acquisition amnesic treatments to become effective. For example, injection of protein synthesis inhibitor into the amygdala after auditory fear conditioning leads to a memory impairment 8 , but not $4 \mathrm{~h}$ later- thus, it is assumed that STM lasts at least $4 \mathrm{~h}$, but not more than $8 \mathrm{~h}$. It should be noted that these are empirically, not theoretically driven characterizations, and are thus premature temporal signatures. Theoretically, in humans, STM can last indefinitely, as long as its contents are actively rehearsed. When this maintenance rehearsal is prevented, the duration of STM might be very short, perhaps 18-20 s (Brown, 1958; Peterson and Peterson, 1959). Therefore, it seems that, at least in humans, LTM starts to form shortly after acquisition. This substantial difference between the apparent duration of STM in humans and the time required to form LTM in animals suggests that either animals can 'rehearse' the contents of STM or that our definitions of STM and LTM are overly simplistic.

Alternative molecular approaches attempt to characterize memory along a continuum of susceptibility to disruption (volatility), where STM-like states can be localized (Sossin, 2008). Importantly, this model, unlike most conceptualizations of STM, can readily explain the existence of LTM in the absence of STM.

In the cognitive research tradition, STM is tightly connected to the influential 'modal model' (Atkinson and Shiffrin, 1968). According to this framework, there are several types of memory stores (sensory memory, STM, and LTM), each characterized by the type of information it can hold, its capacity, forgetting rates and mechanisms, and the processes that maintain information and transfer it to other memory stores. It should be noted that many of the assumptions of this once influential model have been discarded.

\section{Working memory (WM)}

Although related to STM in terms of memory duration, WM represents a more elaborate set of hypothetical structures and processes that focus more on the manipulation of memory content than on its maintenance for a certain duration. However, even Atkinson and Shiffrin did not regard their postulated STM as a pure storage facility, and proposed that STM features cognitive processes for information manipulation, which might explain why they sometimes used the term WM when referring to STM.

Although several models have been proposed, for those concerned with human memory, the term is arguable most strongly linked with the work of Baddeley and Hitch (1974). They proposed a WM system consisting of three units: two content-specific systems (phonological loop and visuo-spatial sketchpad), and a central executive, which manages the two content systems and allocates attentional resources as needed. Baddeley (2000) added an episodic buffer as a component able to bind together the various types of contents of which episodic memories are comprised. The anatomical basis of WM has been intensively studied in recent years, in humans and animals. This work has implicated several brain regions in WM, such as regions of the prefrontal cortex, parietal cortex, thalamus, medial-temporal regions, and cerebellum.

The term WM itself was mentioned first in the animal literature, and is here prominently linked with Honig's conceptualization and Olton's subsequent work (Honig, 1978 ; Olton et al, 1979). Honig distinguished between reference memory and WM (see below), with the latter holding information relevant for only the current task. In his conceptualization, forgetting was a central component process of WM, as its task was to hold information of momentary relevance only. The group around Olton then used the radial-arm maze to study the anatomical substrate of working and reference memory, and found that lesions to the hippocampal system impaired working, but not reference memory.

Importantly, the anatomical substrates of the Baddeley and Hitch on the one hand, and the Honig WM model on the other are different. Humans likely possess both types of WM, and the task may determine which system will be engaged. The Baddeley and Hitch model cannot be tested in animals, as it is unlikely that non-human animals will have a system to process the type of linguistic representations central to the phonological loop.

It is an oversimplification to think of WM in animals as a unified function, with some common neural basis. Although part of the definition of WM in humans depended on its limited capacity, this turned out not to be the case with spatial WM in animals (eg, Roberts and Smythe, 1979). As we see below, it may be most profitable to think about WM as merely a particular state within a LTM (representational) system.

\section{Reference memory}

Reference memory represents knowledge for aspects of a task that remain constant between trials. Originally, the term was introduced to distinguish two types of knowledge rats may retain in a radial-arm maze task: knowledge about which arms of the maze always contain a food reward in each trial (reference memory) and memory for the arms that have already been visited in search for food in the current trial (WM). Reference memory, unlike WM, is subject to memory consolidation, that is, progressive stabilization over time that requires the synthesis of new RNA and proteins, and the implementation of long-lasting morphological changes of synapses in neurons participating in memory representation. Although introduced and to this day mostly used to describe behavior and task requirements for spatial tasks (mainly radialarm maze and the Morris watermaze), reference memory represents an operational definition that cannot be exclusively tied to a specific experimental paradigm. How the term maps to modern concepts of human memory cannot be conclusively determined, although, given the operational definition alone, reference memory on a basic level resembles semantic rather than episodic memory, that is, knowledge that is common across episodes rather than specific to a single specific event.

Reference memory represents, like any other form of LTM, the end point of a series of processes that, beginning with sensory transduction, attention, and encoding, result in long-lasting behavioral changes, from which the existence of memory is inferred. Consequently, pharmacological interventions at any point in this series of processes can affect performance in memory tests. Early studies in spatial reference memory in the radial-arm maze (eg, Olton et al, 1979) suggested that the hippocampus was required for WM, that is, keeping track of which arms of the maze had been visited in each trial, but not for reference memory, that is, knowledge of which arms always contain food. However, this anatomical distinction had to be abandoned in light of evidence (eg, Jarrard, 1978) that animals with pre-training lesions to the hippocampus were impaired in acquiring reference memory in the radial-arm maze, and in view of results showing that it is the spatial nature of the radial-arm task, rather than the working or reference memory requirement, that determines hippocampal involvement (Nadel and MacDonald, 1980). It seems, however, that while the initial acquisition of reference memory requires the hippocampus, long-term retention of successfully acquired reference memory may critically depend instead on cortical structures (Barnes, 1988). This temporal pattern of memory reorganization, which can be found in a number of initially hippocampus-dependent tasks (eg, the Morris watermaze, contextual fear conditioning, socially acquired food preference, contextual fear conditioning, and others), is referred to as systems consolidation.

\section{LTM}

Supposedly without limits on capacity, LTM refers to memory that can last for days, weeks, months, and years. Given the traditional view that the end of STM marks the beginning of LTM, however, it is, at least according to these definitions, conceivable that LTM begins within minutes after memory acquisition. Presumably, LTM can store information from all sensory modalities that can be perceived. In humans LTM includes both explicit and implicit forms, each of which has its own characteristic acquisition and forgetting functions, and each of which appears to depend on somewhat distinct neural systems. In animals, the distinction between explicit and implicit memory is harder to draw, but nonetheless there is strong evidence for separable systems along the dimension of the kind of information a given system processes (see main text) 

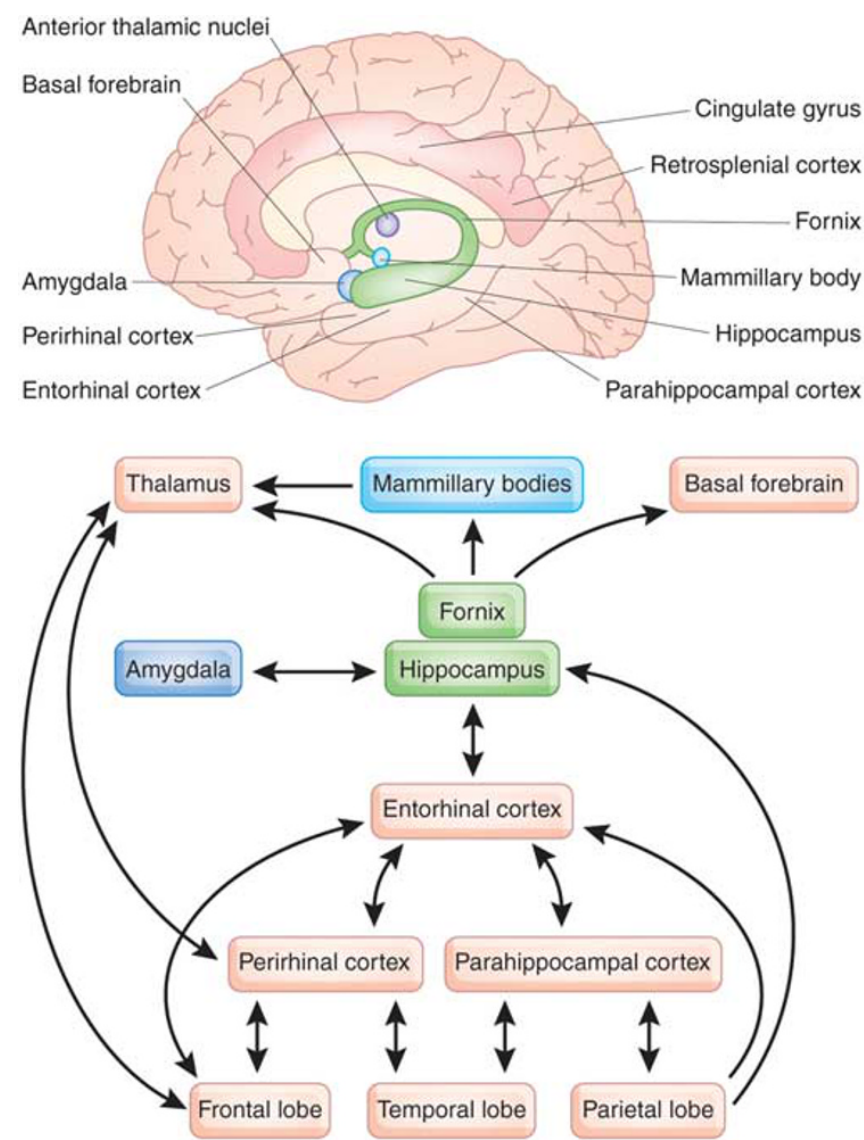

Figure 1. Regions involved in episodic memory. (a) Brain areas important for human episodic memory. (b) Selection of known uni- and bidirectional connections between the major regions of the medial temporal lobe memory system. Figure adapted from Aggleton and Brown (1999) and Bird and Burgess (2008).

organized with respect to various theoretical positions or by reviewing the many studies that have probed consolidation. It is beyond the scope of this paper to fully consider either the broad range of theories or the enormous outpouring of data that characterize this field. Instead, we will use one prominent theory to organize our discussion, and will refer to other theories as required.

An early general framework for understanding systems consolidation is embodied within the 'MTL memory system' hypothesis (Squire and Zola-Morgan, 1991; Squire, 1992, 2009). This approach has occupied an important position among theories of how memory is organized in the brain. Its assumption that the MTL played a special role in LTM, and only in LTM, seemed to give a reasonable account of much of the data when first proposed. Given the prominence of this model, we will use its major postulates to organize a broad discussion of memory systems. This review will lead us to describe a contrasting view that memories, and the knowledge they depend on, are distributed across many brain areas, including areas that have classically been thought of as being occupied with perception rather than memory.

\section{THE MEDIAL TEMPORAL MEMORY SYSTEM HYPOTHESIS}

The MTL (see Figure 1) memory hypothesis was built on several ideas already in the literature, including the notion that there are multiple memory systems (see above), and that the MTL, possibly through the agency of long-term potentiation mechanisms, rapidly forms a cartoon (Nadel and O'Keefe, 1974) or index (Teyler and DiScenna, 1986) that serves to bind cortical sites collectively representing memory. To these notions it added the hypothesis that the MTL is specialized for LTM only, but in a time-limited manner (Squire and Zola-Morgan, 1991). That is: (1) the 'neocortex is thought to underlie perception and immediate (STM) memory', while 'these capacities are unaffected by MTL damage'; and (2) the role of the MTL system 'is only temporary', and 'many kinds of learning abilities' lie outside its province (quotes from Squire and Zola-Morgan, 1991, $\mathrm{p}$ 1384-5). In this initial formulation, the MTL memory system was specifically connected to conscious recollection, but more recent work has shown that this is not the case (cf Henke, 2010 for a review of this issue). More recent refinements have added further assumptions related to differentiation of functions within the MTL (Squire et al, 2007): (3) within the medial temporal system, there is no strict division of labor between regions engaged in memory for single items or for associations, nor is there separation between portions of the MTL with respect to the memory functions of 'familiarity' and 'recollection'. Each of these major assumptions of the MTL memory system view has been the focus of extensive research, to which we now turn. It is beyond the scope of the present effort to review these assumptions in exhaustive detail; rather, we attempt to spell out the issues and provide a sense of current thinking.

\section{IS THE MTL ENGAGED IN PERCEPTION?}

The MTL memory system idea is but one of the many psychological theories that draws a sharp line between perception and memory. Although most textbooks in the field respect this line, there are now reasons to suspect that any sharp delineation is bound to be an oversimplification. From the perspective of perception, there is considerable evidence that even the most basic of perceptual processes, such as figure-ground separation, are subject to top-down effects from memory systems (eg, Peterson, 1994; Peterson and Gibson, 1994; Peterson and Skow, 2008). The idea that perception proceeds without influence from previous experience is no longer tenable. Operationally, perception is separated from memory by the presence or absence of the inputs upon which performance is to be based. In practice, this distinction can sometimes be less than clear. Although the relevant stimuli may all be present, the subject may or may not be able to sense them simultaneously. If not, then something like immediate memory or working memory must be invoked to account for a subject's ability to take them all into account in performing the task. 
This distinction is not critical in evaluating the MTL memory system hypothesis, as it supposes that the MTL is essential only for LTM and not for perception or working memory. However, there is increasing evidence that MTL structures are engaged not only in LTM functions, but also in perceptual and/or STM processes (eg, Graham et al, 2010; Lee and Rudebeck, 2010).

Studies in both animals and humans have shown that damage in portions of the MTL can cause deficits in perceptual tasks such as visual discrimination that cannot be attributed to impaired LTM. Such data have led to the proposal that the perirhinal cortex processes representations of complex feature conjunctions and thereby plays a crucial role in resolving feature ambiguity (Bussey and Saksida, 2007; Murray et al, 2007; Buckley and Gaffan, 2006). Monkeys with perirhinal lesions are impaired at discriminating morphed pairs of stimuli, particularly when feature ambiguity between the pairs is high (Bussey et al, 2003); monkeys with hippocampal lesions are unimpaired on this task (Saksida et al, 2006).

These results were extended to humans in a recent study by Barense et al (2005). Individuals with focal lesions in the MTL were tested in several tasks requiring the resolution of feature ambiguity. Patients with damage limited to the hippocampus were unimpaired on these tasks, whereas those with damage including perirhinal cortex were impaired when feature ambiguity was involved. Memory load was held constant across all test conditions in this study; variations in performance were related to the perceptual factor of feature ambiguity.

In defense of the MTL memory system hypothesis, it has been argued (eg, Levy et al, 2005; Shrager et al, 2006) that the deficits observed in such tasks reflect the use, by control subjects, of memory strategies and capacities unavailable to the patients with MTL damage. However, recent work using new tasks that eliminate the need for a learning or memory component (Barense et al, 2007) replicated the deficits in patients with MTL damage including perirhinal cortex. Overall, the data suggest that when subjects must distinguish between complex stimuli that share certain features, the perirhinal cortex plays a crucial role independent of the perceptual or memorial nature of the task. Such results argue against the view that perception and memory are separated in the brain: rather, both appear to depend on the same representational systems.

\section{THE MTL AND STM}

The MTL memory system theory interprets the distinction between STM and LTM (see Box 1) in structural terms: the MTL is assumed to be critical for LTM but not STM. As just noted, this claim is closely related to the assertion that the MTL is essential to memory but not perception. Hence, the studies reviewed in the previous section speak to the role of structures in the MTL not only in perception, but also in STM, as many of the tasks used in those studies required the maintenance of information about stimuli over brief time intervals.

Consistent evidence in favor of a role for the MTL in STM, or working memory, was first provided by Ranganath and his co-workers (eg, Ranganath and D'Esposito, 2001; Ranganath et al, 2005; Hannula and Ranganath, 2008). In the initial fMRI study, subjects were presented with unique faces followed by a brief delay (7s) and a probe face, to which they had to respond same or different. Sustained activation was observed bilaterally in the hippocampus in this working memory task. A version of the task requiring LTM, in which subjects were presented a series of faces and a later recognition test, revealed no reliable activation in the hippocampus during either encoding or retrieval. In the most recent paper, Hannula and Ranganath (2008) exposed subjects to sets of four objects in a specific spatial pattern within a three-dimensional grid. After a brief delay, they were presented a test pattern on a grid rotated by $90^{\circ}$, which either matched the original display in terms of object-location relations or failed to match the original display in terms of these relations. Activity in the hippocampus and perirhinal cortex during encoding predicted subsequent accuracy in the short-term decision task. The authors conclude that the hippocampus and other MTL structures contribute to encoding and retrieval of information in visual STM.

Two recent studies of electrical activity in hippocampal networks support this idea that the MTL can play a role in actively maintaining memory representations. Axmacher et al (2009) report a positive relation between hippocampal activation and memory for specific items in a word learning task: items accompanied by hippocampal activation were more likely to be subsequently remembered, whereas those accompanied by hippocampal deactivation were less likely to be remembered. Cashdollar et al (2009) showed that the hippocampal role in supporting working memory might involve coordinating theta-range activity in other brain systems, including the frontal and parietal cortices.

Studies of patients with MTL damage support the view that MTL plays a role in working memory, with some caveats. Hannula et al (2006) initially claimed that the hippocampus is critically important in remembering information across brief intervals. Although others seemed to confirm this claim (Nichols et al, 2006; Olson et al, 2006a, b), Baddeley et al (2010) reported the absence of a working memory defect in a single developmental amnesic (Jon), who has well-confirmed impairments in long-term episodic memory. Further, Shrager et al (2006) reported intact working memory in their patients. In a subsequent report (Shrager et al, 2008), this group suggested that impairments only arise in such patients when performance in control subjects depends on LTM, that is, when the memory load exceeds the capacity of working memory. However, their conclusion requires the assumption that retroactive interference affects STM, but not LTM, a claim that is almost certainly wrong.

Evidence in support of the view that MTL plays a role in STM as well as LTM comes from a recent study of 
topographical memory (Hartley et al, 2007). Five individuals with focal damage in the hippocampal region were tested on spatial and non-spatial tasks involving either no delay or a 2-s delay, thereby taxing STM. No impairments were observed on the non-spatial tasks in any of the patients. All of the subjects were impaired on the spatial memory task; three of the five were impaired on the spatial perception task, whereas two of the subjects performed at control or better levels on the perception task. The authors argue that representations in the intact parahippocampal region of these subjects might have been sufficient to support performance on this task.

Overall the evidence suggests that the MTL might not be needed for all forms of working memory, but that many working memory tasks, especially those involving certain forms of spatial processing, require hippocampal participation. Similarly, tasks involving STM for object representations seem to engage the perirhinal cortex. This way of understanding the data fits best with a view of memory systems emphasizing the nature of the representations (eg, spatial, object, etc), rather than the stage of memory involved (eg, working memory or STM $v s$ LTM).

\section{DOES THE MTL PLAY A TEMPORARY OR PERMANENT ROLE IN MEMORY?}

As noted, the MTL memory system hypothesis argues that the hippocampal formation is essential for encoding explicit memories, but not for retrieving them after consolidation (eg, Squire and Alvarez, 1995; McClelland et al, 1995). This position has come to be known as the 'standard model of memory consolidation'. We have argued instead that the hippocampal formation is essential for encoding and retrieving episodic memory irrespective of a memory's age, but that a different pattern emerges for semantic memory (eg, O'Keefe and Nadel, 1978; Nadel and Moscovitch, 1997, 1998). The latter proposed an alternative, the 'multiple trace theory', which argues not only that remote episodic memories continue to depend on the hippocampal formation, but that re-activating a memory causes re-encoding that can modify the existing memory representation (Figure 2).

The earliest data bearing on the question of whether or not the MTL plays a permanent role in memory came from the study of amnesic patients, such as HM, who were reported to be incapable of acquiring new memories, and capable of retrieving old memories as long as they were sufficiently remote. Closer scrutiny of this question, however, has thrown these conclusions into doubt. There is now evidence that amnesic patients can acquire new semantic knowledge, albeit very slowly, and only with extensive repetition (Bayley and Squire, 2002; Stark et al, 2005). There is also evidence that when amnesic patients retrieve episode memories these are not normal, in the sense that they lack the rich detail observed in intact individuals (Cipolotti et al, 2001; Rosenbaum et al, 2008;

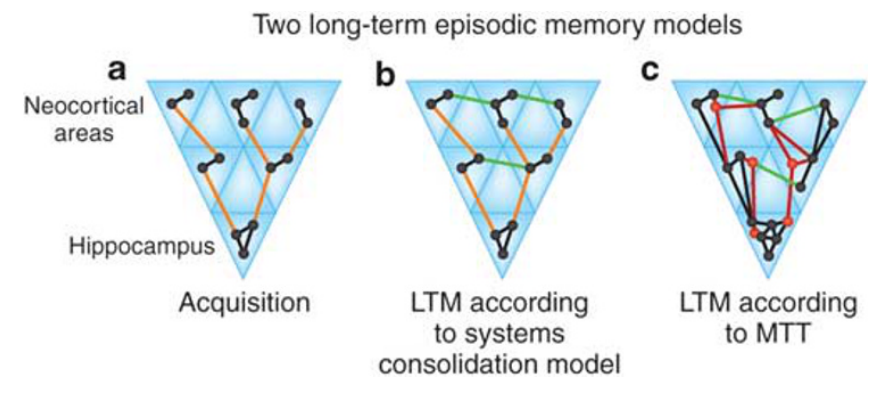

Figure 2. Two prominent theories of how long-term episodic memory might be organized are illustrated. As with most models, these assume that episodic memory draws on representations distributed across many specialized processing areas, and that the hippocampus serves to link and bind areas that have insufficient connectivity at the time of memory formation. (a) Acquisition. The sensory areas processing incoming sensory signals are also the site of storage -in these models, perception and memory are not clearly different. Owing to sparse direct connections between the various brain regions involved in processing and representing the current event, the hippocampus serves to indirectly link them. The hippocampus seems particularly suited to provide this function because: (1) its peculiar architecture features an autoassociative network in subfield CA3 that permits the rapid formation of arbitrary associations required to encode events in one trial. This network can drive attractor states (eg, Wills et al, 2005) that accomplish pattern completion, which is an essential ability for memory recall; (2) it is positioned at the highest level of association cortex, receiving heavily processed signals from all the sensory processing areas, as well as other cortical and subcortical structures (cf Felleman and Van Essen, 1991); (3) it has direct and indirect afferent and efferent connections with most of the neocortex (cf Squire et al, 1989); and lastly, (4) it computes cognitive maps that represent allocentric knowledge (O'Keefe and Nadel, 1978), providing a 'scaffold' to encode sensory experiences within the spatial context of occurrence, thereby critically providing the spatial signature that characterizes event memory (Tulving, 2002a). (b and c) Re-activation of hippocampal traces (which may occur during sleep, for example, Wilson and McNaughton, 1994), leads to co-re-activation of the not yet fully linked neocortical processing areas, which in turn promotes creation of direct links (green lines) between them, or the strengthening of pre-existing sparse connections that initially are not sufficient to support memory. The standard systems consolidation model (SCM) and multiple trace theory (MTT) differ with regard to the involvement of the hippocampus in memory over time. According to SCM (b), initially hippocampal-dependent episodic memories become independent of the hippocampus, owing to the establishment of direct neocortical links between the elements that constitute memory for an event; the state of the hippocampal trace is unclear, as it is either lost or continues to exist even though no longer essential to memory retrieval. The model accounts for the fact that recent memories are more susceptible to hippocampal damage than remote ones by assuming that only when systems consolidation is complete can neocortical circuits faithfully carry out the binding functions of the hippocampus. On the other hand, MTT (c) argues that the hippocampus is always involved in the retrieval of an episodic memory, as only the hippocampus can represent spatial context, and hence only the hippocampus can provide linkages to all the details making up a fully elaborated episode memory. Damage to the hippocampal formation will thus result in a flat temporal gradient of retrograde amnesia - even remote event memories cannot be recalled in their entirety (eg, Lehmann et al, 2007). MTT assumes that each time a memory is re-activated, the hippocampal trace that supports it is expanded and hence strengthened. It is argued that such trace expansion permits the addition of new content to existing memories (new nodes and connections in red). 
Poreh et al, 2006). This debate, however, remains unsettled, as there is some evidence suggesting normal remote memory retrievals in amnesic patients (Bayley et al, 2003). Similar issues arise when the memories involve spatial information. Teng and Squire (1999) showed that amnesic patients can retain remote spatial memories. Rosenbaum et al (2000) confirmed the finding that some aspects of remote spatial memory are retained, but showed that amnesic patients are nonetheless not normal in this regard. Their amnesic subjects retained a coarser spatial representation, devoid of the kinds of details that characterize normal memory.

Differences in how remote memories are assessed, and differences between patients in the various studies, might account for apparent discrepancies in these studies. These problems can be most effectively addressed in animal studies, where lesion site and extent can be carefully controlled. The results seem clear: when spatial tasks are used, there is no RA gradient following hippocampal lesions (Clark et al, 2005a, b). Some have claimed that even in nonspatial tasks retrograde gradients are flat (Sutherland et al, 2008). Thus, lesion studies support the claim that the hippocampus is always required when either episodic or spatial memory is involved. More recent work addresses the question raised by Rosenbaum et al (2000): are the remote memories retained after hippocampal lesions less detailed than normal? Wiltgen et al (2010), using a contextual fearconditioning paradigm that initially requires the hippocampus, showed that memory for this situation loses its precision over time, and as it becomes independent of the hippocampus (see below for further discussion of this point).

Another approach to this question involves the use of functional neuroimaging to detect neural activation during recall of episodic memories. In this case, one can readily compare episode memories of different ages to directly address the question of whether hippocampal formation is activated during retrieval of both recent and remote memories. The data on this are nearly unanimous in showing robust hippocampal activation in both cases (Nadel et al, 2000; Ryan et al, 2001; Maguire et al, 2001; Conway et al, 1999; Maguire and Frith, 2003; Addis et al, 2004; Gilboa et al, 2004; Piolino et al, 2004; Viard et al, 2007; but see Piefke et al, 2003). The possibility that the observed activation reflects not retrieval but encoding of the current circumstance (Buckner et al, 2001) is hard to refute, as some encoding is indeed likely to be happening, and is predicted by all current models of hippocampal function. Multiple trace theory (Nadel and Moscovitch, 1997) proposed that when a memory is retrieved it is indeed actively re-encoded. Several attempts to separate encoding from retrieval have shown that the activation observed during retrieval of remote episodic memories is highly likely to reflect actual retrieval rather than mere encoding (Gilboa et al, 2004; Viard et al, 2007).

A central claim of the standard model of consolidation is that once an engram has been stabilized (either at the cellular or systems level), it is stabilized for good. This idea was challenged quite early by Lewis and others (eg, Lewis et al, 1968; Misanin et al, 1968; Lewis, 1979), who pointed out that even apparently stabilized memories can be disrupted when brought back to an active state, but this early challenge was more or less ignored. More recently, several research programs have re-energized this challenge to consolidation theory by showing once again that apparently fully consolidated memories are still open to disruption. Sara and her co-workers, for example, showed that re-activating a previously consolidated maze learning memory renders it susceptible to disruption by, for example, systemic injection of the NMDA receptor antagonist MK-801, or the beta antagonist timolol (Przybyslawski and Sara 1997; Roullet and Sara, 1998; Sara, 2000). Nader et al (2000) showed the same effect using fear conditioning and injections of anisomycin into the amygdala. Crucially, in all these studies such injections had no effect unless the memory had been re-activated, and only if they were administered in close proximity to re-activation. The overwhelming body of data suggest that re-activation induces plasticity in LTM representations, rendering these re-activated memories as fragile as they were shortly after initial acquisition. It seems that re-activation necessitates re-consolidation of memory (Nader and Hardt, 2009). Some clinical applications of this effect will be discussed below.

Re-consolidation effects have been documented on the systems level as well. As noted above, the standard model of systems consolidation assumes that episodic memories only transiently depend on the hippocampus, and that RA should be temporally graded. Although not explicitly stated, this account implicitly assumes that systems consolidation - the process transforming a hippocampus-dependent to a hippocampus-independent memory - is irreversible and thus unidirectional. As with cellular consolidation, this appears not to be the case. Debiec et al (2002) investigated whether re-activating contextual fear memory in rats, at a time when it no longer required the hippocampus for expression, could renew hippocampal involvement. In the absence of re-activation, hippocampal lesions made 45 days after training did not diminish fear of the conditioning context. However, when the fear memory was re-activated (ie, expressed) before making a lesion, rats no longer feared the conditioning context when exposed to it some time after recovering from surgery. This result suggests that re-activation returned a hippocampus-independent memory to hippocampal dependence, and made it susceptible to hippocampal damage again. However, within 2 days after re-activation, re-activated contextual fear memory no longer required the hippocampus for expression, indicating that re-activation-induced systems-level memory reorganization processes take much less time than the reorganization process following initial acquisition. As we will discuss at some length below, changes in hippocampal dependence observed in the time following acquisition and re-activation are attended by certain qualitative transformations, which can help us understand this complex set of results (see also Figure 3). 
Possible effects of challenging systems reconsolidation

a

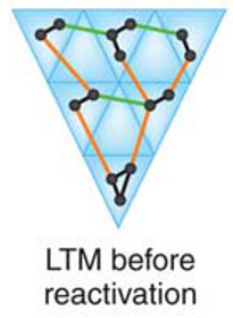

b

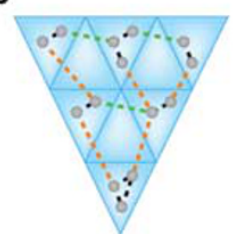

LTM after reactivation
C

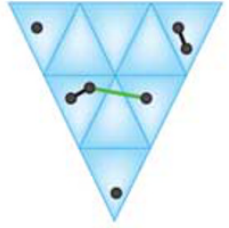

Widespread memory deterioration d

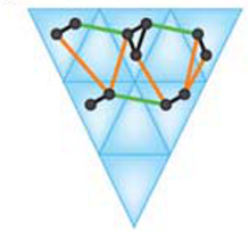

Loss of hippocampal memory component e

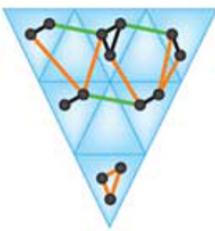

Disconnected

hippocampal memory
Figure 3. Infusing protein-synthesis inhibitors into dorsal hippocampus after re-activating contextual fear memories that no longer required the hippocampus for expression resulted in the loss of contextual fear (Debiec et al, 2002). Several explanations of this effect are illustrated. (a) Memory representation according to multiple trace theory (MTT) before memory re-activation. The contextual fear memory consists of components distributed across the neocortex and the medial temporal lobe, including the hippocampus. (b) Recalling this type of memory may lead to plasticity in all re-activated areas. Impairing hippocampal function at this point can lead to several outcomes: (c) Atypical input from an impaired hippocampus may disrupt re-stabilization of re-activated memories in areas receiving input from the hippocampus, so that the entire complex of representations is affected and degraded. (d) The intervention may only affect the hippocampus, leaving representations in other brain areas intact. However, the removal of the hippocampal component results in an inability to retrieve the memory, as crucial information with regard to the spatial context in which the event took place is lost. (e) The hippocampal representation remains, but is decoupled from brain areas representing other aspects of the memory, leading to a lack of fear.

\section{THE MTL, RECOLLECTION AND FAMILIARITY}

Memory is probed in several ways, most commonly by recall or recognition tests. The importance of the MTL in the recall of episodic memory is not in dispute, but considerable debate surrounds the issue of recognition. The MTL memory hypothesis holds that the MTL is essential for recognition, no matter how it is accomplished. This idea was challenged by Brown and Aggleton (2001), see also Aggleton and Brown (1999), who argued that different brain systems, and processes, are engaged when recognition is accomplished in each of the two ways: either by explicitly recollecting the circumstances under which the item or event was experienced, or by experiencing a feeling of familiarity with the item or event without any explicit recollection. Their claim was that the hippocampus proper was critical for recollection, whereas the rhinal cortex was critical for familiarity. The literature on this issue is quite voluminous, and cannot be reviewed in depth here (for a review, see Eichenbaum et al, 2007, and for a recent study, see Vann et al, 2009).

It has been recently suggested that data supporting the idea that separate brain systems are devoted to familiarity or recollection can be explained in terms of weak (familiar) $v s$ strong (recollected) memories instead (Squire et al, 2007). In a direct test of this view, Cohn et al (2009) showed that activity in the hippocampus reflected actual recollection rather than memory strength. This idea was also tested in a recent study (Easton and Eacott, 2009) in which rats were trained on two E-shaped mazes, using two distinct objects ( + and $\boldsymbol{\Delta}$ ) and different wall linings to create separate contexts (Figure 4b). Animals learned that in context $\mathrm{A}$ the objects were located in one left-right arrangement, whereas in context B the objects were in the opposite, that is, right-left arrangement. After learning these context-object arrangements, rats were given a relatively long exposure to one of the objects (in a separate box) before being placed in one of the two E-mazes and allowed to seek out the relatively novel object, as rats typically do. In this task, the initial choice, made while the rat is in the central arm of the $\mathrm{E}$, which did not contain an object, depends on episodic memory - in which an object is to be found in a specific context. Once the animal makes a choice, it can now spend as much time as it chooses with each of the two objects. Here, its preference, or exploratory activity expressed toward an object, reflects the relative familiarity it has with each object, as influenced by the preexposure to one of the objects beforehand-as the preexposed object should be more familiar, the rat should explore it less than the object it had not seen before. Easton and Eacott showed that while lesions in the hippocampus disrupted performance on the episodic component of this task (ie, whether to turn left or right depending on the context the rat was placed into), they had no effect on the familiarity component. An explanation of these data in terms of differential memory strength is implausible since the recollection and familiarity data involved the same animals, trials, and objects.

Describing this study allows us both to address a specific question and also to introduce an example of the kind of animal-based paradigms that should prove useful in designing studies in the future. Such paradigms address specific forms of knowledge, rather than hypothesized types of memory, and in so doing appear to identify more precisely what various brain regions are actually doing.

\section{THE MTL, ITEMS AND ASSOCIATIONS}

A final postulate of the MTL memory system hypothesis to be discussed is the assertion that the MTL is equally engaged when subjects are learning items or associations between items. This notion is related to the issue just discussed concerning recognition memory: the idea that it can be accomplished via recollection or familiarity. One can imagine that even when learning about isolated items, what 
Some paradigms to study episodic-like memory in rats

a Basic phenomenon. Rats prefer novelty

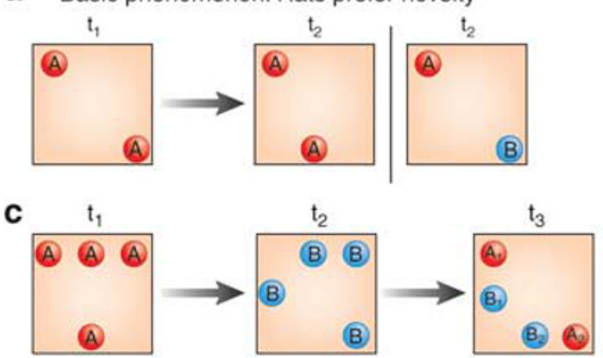

b

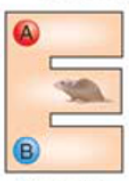

Context 1

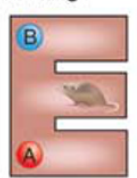

Context 2

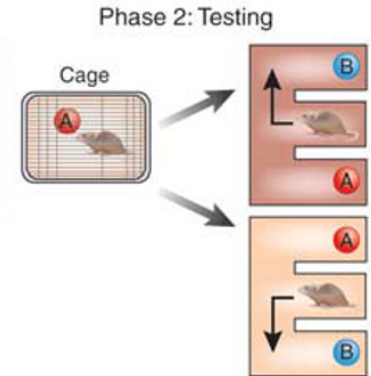

Figure 4. Some paradigms to study episodic-like memory in rats. (a) Rats are attracted to novelty. In order to recognize novelty, they must have knowledge of familiarity, that is, memory for what they have encountered in the past. This is the logic behind novel object preference-based object recognition paradigms. First ( $t$ 1), rats are exposed to two identical copies of an object ('A'). As both of these objects are identical and thus equally new, rats tend to spend about the same amount of time exploring each. Varying the amount of exposure moderates how long memory for these objects may last. Later (t2), rats are exposed to either an old or a new object (replacing one copy of one old object at its original location), or they are exposed to the same objects as during sampling (t1), but with one object moved to a new location. If rats have memory for the old objects and their locations at t2, they will explore the novel object, or the old object in a new location, more so than the familiar object or familiar location. These paradigms have the advantage that no extrinsic motivation needs to be supplied to provoke the behavior of interest. However, if needed, an emotional component can be easily included, which will permit the study of the effect of positive and negative affect on memory organization and persistence within this paradigm. (b) A recently developed paradigm (Easton and Eacott, 2009) based on the novel object preference to study memory for what-where-when (see text for explanation, section 'The MTL, recollection and familiarity'). (c) Another episodic-like task exploiting novel object preference (Kart-Teke et al, 2006). During sampling (t1), rats are exposed to four identical copies of an object, and at (t2), they are presented with four new objects. Some objects during $\mathrm{t} 2$ are at positions that have been occupied by an object during $\mathrm{t} 1$, and vice versa. Finally, during the test (t3), rats are presented with two objects from $\mathrm{t} 1$ and two from $\mathrm{t} 2$. Two of the objects are at their original positions (A1 and B1), and two are at positions that have been previously occupied by objects: one object from phase t1 (A2) is at a location where an object $B$ had been placed during phase $t 2$, and one object from phase t2 (B2) has been placed at the location occupied by an A object during phase $\mathrm{t} 1$. Thus, during the test phase (t3) rats are confronted with varying degrees of novelty - the B objects from phase t 2 had been more recently experienced than the A objects from phase t1, and thus the A objects should attract more exploratory activity. However, some objects are at new locations. If rats possess episodic-like knowledge of what-when-where, they should explore the misplaced objects (A2, B2) more than those at their original location (A1, B1).

a subject learns includes the association between the items and the context in which they are experienced. In this sense, even 'item' learning is associative. However, it is also possible that one can learn something about an item without this association to context - and 'recognition by familiarity' is an example of how this might be manifested in behavior. Given this linkage between the 'association $v s$ item' debate and the 'recollection $v s$ familiarity' debate, it is hardly surprising that these two debates have frequently been conflated in the literature, and that it has proven hard to decide the issue one way or the other.

As regards items and associations, this conceptual unclarity is matched by equivocal data from patients with hippocampal damage: there are reports of equivalent deficits in item and associative tasks (Stark et al, 2002; Stark and Squire, 2003), as well as reports of spared item learning and impaired associative learning (Kroll et al, 1996; Holdstock et al, 2005; Giovanello et al, 2003; GoodrichHunsaker and Hopkins, 2009). Data from neuroimaging studies favor the view that items and associations engage distinct circuits within the MTL (Davachi et al, 2003; Kirwan and Stark, 2004; Dougal et al, 2007; Staresina and Davachi, 2006, 2008).

The position taken by proponents of the MTL memory system hypothesis on this complicated debate is that differentiation of function within the MTL can best be captured in terms of memory strength rather than memory type. That is, hippocampal involvement signals a stronger memory, whereas parahippocampal or perirhinal involvement signals a weaker memory. As associations are assumed to be stronger than items, and recollection involves stronger memories than familiarity, it is argued that the data showing selective hippocampal engagement by associations and recollection merely reflect these differences in memory strength.

This idea has been tested in a recent study by Qin et al (2009), in which processes underlying item and associative memory were clearly separated, and in which differences in memory strength between the two were balanced as carefully as possible. In line with the view that there is distinct differentiation of function within the MTL, Qin et al (2009) showed a subsequent associative memory effect in the hippocampus and a subsequent item recognition effect in the parahippocampal cortex. They note that since confidence (and hence memory strength) was similar for these two aspects of memory, the fact that differentiations were seen between associative memory and recognition is inconsistent with the memory strength hypothesis.

\section{THE MTL MEMORY SYSTEM REVISITED}

Our review suggests a lack of support for most of the key postulates of the MTL memory system hypothesis. Given this, we must consider the possibility that the broad framework within which this hypothesis is articulated is 
misguided - should this turn out to be the case, it would have important implications for how we think about the organization of what we call memory, how we think about studying memory and its pathologies, how we use animal models to understand it, and how we can manipulate it pharmacologically.

The broad framework encompassing the MTL memory hypothesis is one in which the brain is neatly organized into systems (black boxes) labeled 'perception', 'STM', 'attention', 'LTM', and the like. Within this framework, it is often argued that separate brain systems account for such things as 'priming', 'recognition', and 'recollection', and that memory is fundamentally about the past. Our review suggests these assumptions are open to serious question. Further, much recent evidence makes it clear that 'memory systems' in both humans and animals are as engaged by thinking about the future as when retrieving the past (eg, Buckner, 2010; Szpunar, 2010, Dragoi and Buszáki, 2006; Wood et al, 2000; Johnson and Redish, 2007). The last of these documents a phenomenon in rats that closely resembles what Tulving (2002b) termed 'mental time travel'. Rats were trained to run loops on a maze with several decision points. In one task, the critical choice was to turn left or right, and only the path to either the left or right led to a food reward. Which path was rewarded changed from day to day. After being pre-trained to proficiency, the animals were implanted with electrodes aiming at the CA3 field of the dorsal hippocampus to determine place field activity during task performance. A short-lived (ca. $600 \mathrm{~ms}$ long), but very interesting pattern of neuronal activity was observed at the critical decision point, when rats briefly paused to 'determine' whether to turn left or right: place field neurons fired as if the animal was 'simulating' a path before actually taking it. That is, the neurons with place fields along that path fired in sequence, even though the rat was stationary. This remarkable phenomenon is akin to the constructive episodic simulation hypothesis proposed by Schacter and Addis (2009), who suggest that the human episodic memory system (of which the hippocampus is a central part) 'enables past information to be used flexibly in simulating alternative future scenarios without engaging in actual behavior' (p 1246).

Abandoning the approach upon which the MTL memory system was based requires the adoption of an alternative framework that can better account for the data discussed above. We suggest that instead of thinking about the brain as being organized into separate systems for perceiving and then storing records of experience, it is best to think about it as being organized into systems that represent types of 'knowledge' and access those representations to process, store, and use information (Nadel, 2008). Although we will focus on applying this representational view largely to episodic and semantic memory, it would clearly also apply to habit memory, emotional memory, and other types of memory that have been discussed in the literature in recent years. In each of these cases, what has been acquired is a certain kind of information, about responses, or emotions, for example, and the brain systems engaged can readily be viewed as both processing and storing such information. In this view, there are neither perceptual nor memory systems per se. This is not a new idea: indeed, variants of it have been proposed over the past 40 years, including the position taken by O'Keefe and Nadel (1978).

\section{IMPLICATIONS OF A REPRESENTATIONAL VIEW OF MEMORY}

Representational systems of the kind we are proposing can be characterized in terms of their contents - what they are about, and in terms of their processing function - what they do. Although there is increasing convergence around the idea that brain systems should be thought of in this representational framework (eg, Konkel and Cohen, 2009; Kumaran and Maguire, 2009; Saksida and Bussey, 2010; Squire et al, 2007), there is considerable disagreement about whether it is best to characterize a given system in terms of content, process, or a combination of the two.

Nearly 200 years ago, Johannes Müller enunciated the principle of 'specific nerve energies'. In his view, nerves were not passive conductors, each had its own special qualities. No matter how visual nerves are stimulated, they can only transmit visual information, and cause a visual experience. The modern conception of this idea differs from Müller's, which emphasized the special qualities of the sensory nerves themselves.

We now understand that all nerves work the same, and that felt experience is dependent on the brain location to which nerves project, rather than the nerves themselves. This is not to say we understand why activity in neurons in the visual cortex causes us to 'see' while activity in neurons in the auditory cortex causes us to 'hear' - the problem of phenomenology remains unsolved. However, it is to say that activity, in particular neural ensembles, is always 'about' something specific. Unlike the circuits in a desktop computer, the circuits of the brain are not endlessly interchangeable. Developmental plasticity, and responses to injury, do allow for a certain amount of re-programming, but there are strict limits to this plasticity.

The principle of specific nerve energies has found voice in the modern idea that neural systems are 'content addressable'. Content addressability denotes the systematic relationship between the content of an experience (both subject matter and qualitative feel) and the brain networks involved in representing it. As the content of a signal determines which circuits in the brain it will activate (by Müller's principle), this very content will necessarily re-activate the same circuits, or a subset of those circuits, when experienced again. An interesting facet of content addressable systems is that they require pattern completion mechanisms for accurate information retrieval-as retrieval cues are typically either incomplete or contain some level of distortion. It is perhaps not surprising, in 
this context, that pattern completion mechanisms are a prominent feature of virtually all computational models of the hippocampus, beginning with Marr (1971).

Such considerations argue against understanding representational systems as being primarily organized around temporal factors (short-term vs long-term) or computational principles (associations, or relations, or conjunctions, $v s$ items or elements). Instead, they suggest that brain systems are organized in terms of the kind of information they process. This does not rule out the importance of temporal factors or computational goals - rather, it asserts that it is the content of a representation that matters to the brain in the first instance. This conclusion argues against the approach to hippocampal function that stresses its role in relational processing, no matter the nature of the relations in question (eg, Cohen and Eichenbaum, 1993; Konkel and Cohen, 2009). In a direct test of the relational memory hypothesis, Kumaran and Maguire (2005) showed that the hippocampus was preferentially engaged when spatial, but not social, relations are being processed. A similar emphasis on spatial relations was observed by Hoscheidt et al (2010). These and other results converge on the idea that the hippocampus acts to relate items and the contexts in which they occur (Ranganath, 2010), a conclusion similar to the one reached by O'Keefe and Nadel (1978).

A representational perspective influences the questions we ask about memory and the brain. The first, fundamental, question concerns the kinds of knowledge that complex organisms need to represent in order to behave adaptively. Put most succinctly, an organism needs to store knowledge about what it experiences, where and when things happened, who was involved, the value of the things experienced, and how to act in the future when confronted with similar situations. Some kinds of knowledge are inferred rather than experienced. Perhaps, the best example concerns why things happen. Organisms make inferences about causality, even though these are rarely backed up by direct experience, and these inferences become an important part of their knowledge base.

Given the existence of these various kinds of knowledge representations, we want to know how they are created and stabilized in the nervous system, how they are deployed in various tasks, what happens to representations with the passage of time, what happens when representations are activated, and if representations can be updated. However, there are other kinds of questions to be asked, perhaps most germane to readers of this journal: how do we apply this new terminology of knowledge, rather than memory, systems to designing animal models? How does this influence our approach to understanding disturbances of memory, and our thoughts about treating such disturbances pharmacologically? The next section of our review will focus on these kinds of questions, most specifically on the ones that play out at the systems rather than cellular level. Although we will still talk about 'memories', it should be understood that we are now talking about knowledge systems whose contents are used whenever memory comes into play.

\section{HOW IS KNOWLEDGE REPRESENTED IN THE BRAIN?}

The current short answer to this question appears to be: as patterns of altered synaptic 'weights' in networks of neurons. Having said this, it is perhaps more accurate to say that we do not really know the answer to this question. Although synapses look to be the site of the action, there are reasons to believe that individual dendrites may be important as well (eg, Parvez et al, 2010). For present purposes, we can abstract away from this debate and settle on the notion that knowledge is represented in ensembles of neurons. In some cases, these are confined to local sites, and in others, the ensemble includes widely distributed elements. Knowledge also appears to be represented in the patterns of activity within and across neural ensembles. This can involve both the frequency of firing (rate codes) and the pattern of firing (temporal codes) as seen in hippocampal place cells, for example Harvey et al (2009). Oscillatory states such as theta and gamma seem critical to determining information flow within the brain and play a significant role in MTL memory functions (Sederberg et al, 2003; Montgomery and Buzsáki, 2007; Guderian et al, 2009; Colgin et al, 2009; Tort et al, 2009; Shirvalkar et al, 2010).

\section{WHAT HAPPENS IN THE BRAIN WHEN MEMORIES ARE RETRIEVED?}

To start, we must recast the question: what happens in the brain when knowledge representations are accessed in the service of memory? Are the same brain structures engaged in encoding and retrieving representations? Do the brain structures engaged by retrieval change with the passage of time? Do representations, and hence the memories dependent on them, change in some qualitative way with the passage of time? What impact does re-activating a representation, and retrieving a memory, have on the representation itself?

Before addressing each of these questions in turn, we need to be clear what kinds of memory representations we are, and are not, talking about. As indicated earlier, we are largely confining ourselves to what has been called 'explicit' or 'declarative' memory. As noted, there is a general agreement that there are two rather different kinds of explicit memory - episodic memory and semantic memory (cf Tulving, 1972, 1983). Many of the debates surrounding the questions we raised above turn on distinctions between these two kinds of memory. Episodic memory involves information about the spatial and temporal context of an event. Thus, at a minimum it must engage representations of where an event happened, when it happened, and what it involved. Semantic memory does not include contextual attributes, but rather involves knowledge of the world 
(facts, concepts, etc) that one acquires through episodic experience-what knowledge. The fact that both episodic and semantic memory involves what we are calling what knowledge suggests that there are bound to be important interactions between these two forms of explicit memory.

As stated earlier, Tulving (2002b) goes further in defining episodic memory, claiming that it also entails 'mental time travel', a conscious sense that one is re-experiencing something from the past. Insofar as it is impossible to verify such mental states in animals, those seeking to explore the neural correlates of episodic memory in animal models have resorted to talking about episodic-like memory (eg, Morris, 2001; Eacott et al, 2005) that focuses on knowledge about what, when, and where. We discuss paradigms designed to address episodic-like memory in animals below.

\section{ARE THE SAME BRAIN STRUCTURES AND REPRESENTATIONS ENGAGED IN MEMORY ENCODING AND RETRIEVAL?}

In an early study addressing this question, Halgren et al (1985) recorded from patients with implanted electrodes, for the purpose of evaluating local neural function before surgery for temporal lobe epilepsy. They showed that disrupting MTL function interfered with both encoding and retrieval of memory. More recently, it has become possible to record from individual neurons in the MTL in such individuals, and this work has provided even clearer evidence that the same or similar circuits in the hippocampal formation are activated by both encoding and recalling episode memories (Gelbard-Sagiv et al, 2008; Chadwick et al, 2010). In a recent review, Danker and Anderson (2010) considered data from a wide range of approaches and concluded that under most circumstances the same neural systems are engaged during encoding and retrieval. As we noted earlier, this appears to also be true for episodic memory, whatever the age of the memory - insofar as the memory in question retains rich details of the original experience.

To return to the issue of whether the same representations are engaged by encoding and retrieval, the situation with regard to semantic memory appears to be different than with episodic memory, in that the role of the hippocampal formation might change with time. In several studies, looking specifically at semantic memory, hippocampal activation was shown to diminish with the age of the memory (Haist et al, 2001, Smith and Squire, 2009). However, the picture is not completely clear, as some have reported the absence of such a gradient with semantic memory (Bernard et al, 2004), whereas others have reported both effects in the same study (Douville et al, 2005). What is more, the hippocampus can be activated in subjects engaged in traditional semantic memory tasks, such as category production (eg, Ryan et al, 2008). In this study, subjects were asked to generate as many items as possible in a category, such as kitchen utensils. Many subjects reported visualizing themselves in a specific context (their own kitchen) while producing items, suggesting that even when retrieving information from semantic knowledge one can engage systems typically involved in representing episodic information such as spatial context.

\section{DO REPRESENTATIONS CHANGE IN SOME QUALITATIVE WAY WITH THE PASSAGE OF TIME?}

There is considerable evidence that memory representations change over time, even if the memories themselves are not actively retrieved. The general idea is that memories lose some of their specificity, becoming in some sense more 'semantic'. Evidence for this kind of transformation comes from studies with both humans and animals, although it remains unclear as to how to understand the mechanisms underlying it.

Recent work with context fear conditioning in animals offers a good example of this phenomenon. The paradigm is widely used and on the surface quite simple. Animals, typically rats or mice, are placed in an enclosed conditioning box within which shocks can be administered. The animals are allowed to explore the chamber for several minutes, and then they receive one or more shocks, before being removed and returned to their home cage. Subsequently, they are placed back in the test context, or a novel context, and their memory is measured in terms of how much fear they show, manifested in this paradigm by immobility, or 'freezing', as escape is not possible.

Initially, fear is context specific; that is, animals freeze when returned to the context in which they were shocked, but not when placed in a novel context. However, with the passage of time, animals trained in one context will begin to freeze when placed in another that shares some of its characteristics. In other words, fear generalizes, and is no longer restricted to the context in which it was trained (Biedenkapp and Rudy, 2007; Wiltgen and Silva, 2007; Winocur et al, 2007).

This shift in behavior is tied to a shift in dependence on the hippocampus. When context fear is still context specific, hippocampal lesions knock it out; when context fear generalizes, hippocampal lesions no longer have this effect (Winocur et al, 2007; but see Wang et al, 2009, for a result showing the opposite effect). These results, and the recent study by Wiltgen et al (2010) described above, suggest that with the passage of time a representation is established outside the hippocampus, one that links fear with a 'degraded' or more semantic version of the context. This allows fear to be expressed in novel contexts that share at least some of the features of the original training context. These results leave open the fate of the representation formed during training that is dependent on the hippocampus, and that supports context-specific fear expression. As we will see below, the results of a recent re-activation 
study are most consistent with the notion that the hippocampal trace persists in parallel with the newly formed extra-hippocampal trace that supports generalized fear.

In work with humans, the term 'semanticization' was coined by Cermak (1984) to account for a transformation from specific (episodic) to more generic, gist-like (semantic) memory over time. Such effects include memories for both highly salient events - the so-called 'flashbulb' memories - as well as every-day events of no special significance. Schmolck et al (2000) asked participants to retrieve memories of how they heard the news of the OJ Simpson murder trial verdict either 15 or 32 months after the event. The accuracy of recollection decreased from $50 \%$ at 15 months to $29 \%$ at 32 months. Only $11 \%$ of the memories at 15 months contained major distortions, whereas over $40 \%$ did at 32 months. Kristo et al (2009) reported on an Internet-based diary study, testing retention of events between 2 and 46 days old. Details were forgotten fastest, but overall all elements of the memories were lost at about the same rate. Sutin and Robins (2007) compared recent and remote memories in a very large sample of young adult subjects and showed that recent memories have more sensory details, are more vivid and coherent, and are more likely to be reported from a first-person perspective. Tollenaar et al (2009) directly compared recent and remote memories in young males and showed that remote memories were, on average, less specific.

One way of understanding this loss of specificity builds on the idea that the hippocampus represents spatial contexts, and that these representations serve as an index binding together the elements of which the context is composed as well as the events occurring within that context (eg, Teyler and DiScenna, 1986; Nadel and O'Keefe, 1974; Nadel and Moscovitch, 1998). With the passage of time, two things happen: first, some of the links to elements are lost, and second, a parallel representation directly linking elements and events, independent of context, develops outside the hippocampus. The former accounts for the loss of specific details and the latter for the generalization of behavior to new contexts.

There is evidence for both of these mechanisms. One view proposes that systems consolidation involves computations extracting the gist of initially detail-rich episodic memories (Nadel and Moscovitch, 1998). Some believe this kind of gist extraction occurs during off-line processing, most prominently in sleep (eg, McClelland et al, 1995). It results in knowledge representations that capture the regularities of experience independent of the contexts in which this knowledge was obtained. Alternatively, perceptual detail may simply be forgotten over time (either due to decay or interference), which finds support in a study of the impact of verbal labels present at encoding on later recognition. Daniel (1972) showed participants a series of images, all presenting systematic variations of different base images (eg, a drawing of a camel, duck, etc). They were shown together with the correct names (eg, 'camel'). Either immediately or up to 2 days later, participants were given a recognition test, in which the studied instance and other non-studied instances that deviated to varying extent from the base object were presented in a randomized order. Daniel found that with increasing retention interval, participants increasingly based their recognition responses on the relation of the test items to the base image rather than to the studied items. Such results, and many like them since that early report, suggest that over time some perceptual details of an original memory fade away and are simply forgotten, whereas a conceptual component, in this case the verbal label, remains.

This discussion makes it clear that representations can change with the mere passage of time. What happens, however, when memories are activated through explicit retrieval?

\section{EFFECTS OF EXPLICIT RE-ACTIVATION}

In principle, re-activating a memory could have several effects: first, re-activation might strengthen the specific neural representations supporting that memory, either through replication or expansion of the neural traces underlying these representations; second, as the work on re-consolidation in animals suggests, re-activation might initiate a period of trace instability; and third, re-activation might permit alteration of existing traces to accommodate new information (cf Hardt et al, 2010a). Until recently, discussions of memory re-activation would have been limited to cases where subjects in an experiment were asked to explicitly retrieve a memory, or were exposed to reminders that might implicitly or explicitly re-activate a memory. The discovery that patterns of neural activity from the waking day are repeated at certain times during sleep has recast the discussion of the impact of memory re-activation. The importance of these 'replays' is only now being investigated, but it has already been shown in several studies that memory strength is related to the extent of such replay (Rudoy et al, 2009; Diekelmann et al, 2009). In what follows, we focus on re-activation of memory that occurs during waking hours.

It is widely assumed that re-activation in the form of recall, or additional training, acts to strengthen memory. However, there remains some debate as to whether this change manifests as an increase in accurate memory recall or some change, or distortion in recall. Bartlett's (1932) seminal work involving repeated reproduction of a story ('War of the Ghosts') showed that with repetition there came increasing schematization and distortion. However, attempts to replicate these findings yielded confusing results (Gauld and Stephenson, 1967; Wheeler and Roediger, 1992; Wynn and Logie, 1998), until Bergman and Roediger (1999) determined the optimal circumstances under which repeated retrievals lead to distortion. What seems to be important is the retrieval instruction: when subjects are simply told to recall the story (as Bartlett, and Bergman and Roediger did), then distortions abound. 
When subjects are instructed, instead, to reproduce the story as accurately as possible, then these apparent distortions diminish greatly. In addition, when repeated recalls are used, any distortions produced on the first recall become highly likely to be repeated on subsequent recalls (Roediger et al, 1996). This suggests that to the extent that re-activation either initiates or somehow yields an altered representation, this new version of the past becomes fixed in place.

All this leaves an unclear picture as to the impact of re-activating a memory. It certainly can strengthen the representations underlying that memory, but it strengthens whatever representations are activated at that time. Since the mere passage of time, as we noted above, can cause a loss of detail as well as a schematization of memories, it seems clear that recalls made some time after initial encoding can have the perverse effect of 'locking in' inaccurate versions of the past. If, for some reason, inaccurate memories are created in the first place, then recalls fairly soon after the event could have the same effect (cf Loftus et al, 1978). Something very much like this could be happening in the context of stress and trauma.

\section{DOES RE-ACTIVATION CHANGE MEMORY?}

A recent animal study suggests that memory re-activation can re-induce hippocampal dependence in a hippocampusindependent memory and thereby alter the re-activated memory's specificity, that is, its contents. Winocur et al (2009) first replicated the well-known effect that, unlike recently acquired contextual fear memories that still require the hippocampus, remote, hippocampus-independent contextual fear memory is less context specific: rats that initially would only fear the original conditioning context expressed after some time fear to contexts in which they had never been conditioned. In another study, Winocur et al (2009) showed that this generalization effect, which is similar to the semanticization phenomenon in humans, occurs also when remote, hippocampus-independent memory becomes re-activated in the original training context, and, as in the study by Debiec et al (2002) discussed above, hippocampal lesions then cause memory impairment. When the hippocampus-independent memory was re-activated in a new context that only partially resembled the original training context, the re-activated memory did not regain specificity and was also less affected by hippocampal lesions. It thus seemed that re-activation in the context in which original learning took place could render a generalized contextual fear memory specific again. It remains unclear as to what happened to the knowledge that could, before re-activation, be expressed without the hippocampus. Resolving questions like these will be important to understand the dynamic organization of memory.

Similar effects of re-consolidation on memory contents have been reported in human studies as well. Walker et al (2003), using a finger-tapping task involving two sequences, reported that re-activating the first sequence before learning the second led to impaired memory for the first sequence. Galluccio (2005) and Galluccio and Rovee-Collier (2005) trained infants to activate a mobile by kicking their foot. After a delay, infants were exposed to the mobile for a brief period of time during which kicking had no effect (noncontingent exposure). Now, some of the infants were exposed to a novel mobile that moved when the infants kicked. The next day, those infants exposed to the novel mobile no longer recognized the originally trained mobile. This did not happen in those infants not exposed to a novel mobile after re-activation.

Hupbach et al $(2007,2008,2009)$ used an episodic memory paradigm involving the learning of a set of objects to assess re-consolidation in humans. Subjects were exposed to a set of 20 small objects and were given up to four trials to learn them. After $48 \mathrm{~h}$, subjects were either reminded of the first session or not, and immediately afterwards learned a second set of objects. After $48 \mathrm{~h}$, subjects were asked to recall the first set. Reminded subjects showed a high number of intrusions from Set 2 when recalling Set 1, whereas subjects who had not been reminded showed few intrusions, demonstrating that the updating of pre-existing memory is dependent on re-activation of that memory. This effect took time to emerge, that is, it was not evident immediately after learning Set 2 . This rules out an explanation based on retroactive interference, which would predict an immediate alteration of memory. Critically, intrusions from Set 1 were not observed if Set 2 was recalled during Session 3, instead of Set 1. The asymmetric nature of this effect argues against any simple 'source confusion' interpretation.

Updating memory of Set 1 by incorporating items from Set 2 only occurred when Set 2 is learned in the same spatial context as Set 1. When subjects are brought back to the spatial context where the first set of objects was learned, memory for that set is re-activated. This re-activation allows the memory for the first set to be modified, or updated, by, for example, incorporating objects from the second set into the original trace. The learning of a second set of objects in a novel context fails to re-activate the memory for Set 1 , leading instead to the creation of a new episodic memory. Thus, participants who learned Set 2 in a different spatial context did not modify the memory for Set 1 . The critical role played by spatial context points directly to hippocampal involvement in this paradigm.

Re-consolidation effects in humans have been reported in a number of other labs, putting this phenomenon on strong footing, and making it clear that re-activation can indeed lead to alterations in the representations underlying memory (Forcato et al, 2007, 2009, 2010; Zhao et al, 2009; Chan et al, 2009). Indeed, post-re-activation liability of established LTM has been used as a possible treatment for psychological disorders, notably post-traumatic stress disorder (PTSD). Brunet et al (2008) provided the first demonstration that aspects of unusually strong, intrusive, and persistent emotional memories can be altered 
pharmacologically after memory re-activation. They treated PTSD patients with propranolol, a beta-adrenergic antagonist, after they retrieved their traumatic memory. Subjects first prepared two written descriptions, or scripts, about two elements of the PTSD-inducing event. After this initial reactivation of their traumatic memory, they received either propranolol or placebo. After 1 week, subjects were exposed to recordings of a $30 \mathrm{~s}$ condensed version of their scripts, and were instructed to imagine the events that were reported. Several measures of autonomic activation were taken during this session (heart rate, skin conductance, left corrugator electromyogram). Heart rate and skin conductance were smaller in the PTSD patients that received propranolol after their first memory re-activation session, and at a level typically seen in individuals who experienced traumatic events but did not develop PTSD. No differences were found in left corrugator response. This study has some methodological shortcomings: autonomic baselines for the participants before entering the study were absent, and the study used only autonomic response as an assay of emotional distress caused by remembering a traumatic experience, providing no information on the emotional strain consciously experienced during recalling traumatic memories. Nonetheless, it was the first study indicating that post-re-activation plasticity might have potential clinical applications.

The finding that post-re-activation administration of propranolol can significantly reduce acquired fear responses has recently been replicated in a more controlled study. Kindt et al (2009) conditioned humans to fear certain spiders presented as images on a computer screen by pairing some images with an unpleasant but not painful electric shock delivered to the wrist. They used a differential fear-conditioning paradigm in which some images were paired with shock, and others were not. Participants were also asked to indicate on a scale the extent to which they expected shock delivery. Thus, their task had a purely emotional component (fear of a certain stimulus), as well as an episodic component (allowing participants to gauge whether a shock will occur). After conditioning on day 1 , participants received either propranolol or placebo, after which their memory was re-activated by a single exposure to the conditioned stimulus. Another group of participants were given propranolol, but no memory re-activation. The next day, all participants received extinction trials (presentations of the conditioned stimuli without shock). Those participants that received propranolol after memory re-activation no longer expressed fear to the conditioned stimuli, whereas those that received placebo or propranolol without re-activation had a robust fear response, which subsided during the extinction trials. The knowledge about which stimuli had been paired with shock (ie, participants' shock expectancy ratings) was not affected by postre-activation propranolol administration. In order to assess whether fear memory expression was only transiently impaired, or whether the treatment lead to a robust loss of the fear response, participants were given reinstatement trials after the extinction trials (ie, delivery of shocks without previous presentation of a conditioned stimulus). Return of fear to the conditioned stimuli following reinstatement would indicate that the fear response was not lost, but rather suppressed. This result was not observed in participants that had received propranolol after reactivation, whereas conditioned fear was successfully reinstated in the other two groups. This study provides two important findings: (a) the systematic administration of the beta-adrenergic blocker propranolol after fear memory re-activation affects the emotional component of this event memory, but leaves intact knowledge about which stimuli had lead to shock administration; (b) the loss of fear seems to be permanent.

The permanence of memory modifications induced by post-re-activation treatments has been shown convincingly by Schiller et al (2010). Instead of using pharmacological interventions to decrease the emotional impact of fear memories, they tried instead to update re-activated fear memories. During training, participants were conditioned to fear one of two colored squares by pairing presentation of that square with a mild electric shock applied to the wrist. The next day, participants received extinction training, in which the conditioned stimulus was presented without subsequent shock. A single presentation of the conditioned stimulus just before extinction reminded one group of participants of the fear memory, whereas another group was not reminded. All groups showed robust extinction of the fear response. The following day, participants again received extinction training. During this re-extinction session, spontaneous recovery (ie, the return of the fear response in the absence of training) was observed in the participants who had not received a reminder on the second day, whereas participants who had been reminded did not show a return of the fear response. This result shows that re-activating a fear memory can allow it to be updated. Although extinction alone can suppress the original fear response, it permits the response to return since the memory is not itself lost. In contrast, a reminder before extinction leads to the updating of the original contingency, rather than to its potentially temporary suppression. About 1 year later, memory for the fear response was re-assessed by a reinstatement procedure (un-signaled presentation of the shock): the re-activation group showed no reinstatement of the fear response, whereas the non-re-activated group did. Thus, the loss of the fear memory in this paradigm was long lasting, lending support to the idea that re-consolidation could be used in treating psychological disorders.

\section{A REPRESENTATIONAL APPROACH: IMPLICATIONS FOR THE USE OF ANIMAL MODELS}

The foregoing shows how one can profitably take a representational rather than memory-focused approach to 
the organization of brain systems. Abandoning the framework within which the MTL memory system hypothesis is embedded has substantial implications for cellular and systems consolidation theory in particular, and for our understanding of the dynamic nature of memory in general. It challenges ideas of a linear memory organization model as proposed in strict versions of the consolidation hypotheses, in which memory travels along a path leading through short- and long-term stores. It seems clear that box-models or encapsulated-module conceptualizations of memory (or the brain, for that matter) inaccurately simplify the dense interconnectivity between representation- and computation-specialized brain areas, and the consequence of these bidirectional projections for memory processing. In so doing, it presents a strong motivation to update the toolbox of methods commonly used in behavioral neuroscience. For example, systemic administration of drugs to impair memory cannot easily increase the resolution of our knowledge if memory is dispersed across a multitude of interconnected areas. Even localized injections of certain drugs can have widespread effects that transcend the boundaries of the targeted brain areas-for example, in order to transiently disrupt hippocampal function the AMPA receptor antagonist CNQX is commonly injected into the hippocampus, where it leads to a dramatic decrease in neuronal firing rate, and, consequently, brain areas that receive input from the hippocampus then receive abnormal signals with unforeseeable consequences for the representations they host (cf Canal et al for a similar effect and argument against the use of protein-synthesis inhibitors in studying memory consolidation).

Recent studies point to the type of high-precision, low side-effect tools that could improve memory research in the future. Sacktor and co-workers (eg, Sacktor et al, 1993; Ling et al, 2002; Pastalkova et al, 2006) showed that LTM requires the continuous activity of the atypical PKC kinase $\mathrm{M}$ zeta (PKM $\zeta$ ), and Migues et al (2010) showed that PKM $\zeta$ maintains memory by regulating the trafficking of GluR2containing AMPA receptors at post-synaptic sites. In their studies using auditory fear conditioning and object location recognition, transient inactivation of $\mathrm{PKM} \zeta$ by, for example, infusions of zeta-inhibitory protein lead to a loss of AMPA receptors at potentiated synapses, and the extent of this loss significantly correlates with memory performance. Unlike other tools commonly used in animal models, targeting PKM $\zeta$ has three basic advantages: (1) the effects do not permanently alter neural function; (2) the treatment can be applied at a sufficient temporal distance from the behavioral assays, allowing one to train and test drug-free animals and to impact memory when it is not in an active state, such as the state of plasticity induced by memory re-activation; and (3) it affects memory by selectively and directly impacting its putative substrate, GluR2-containing AMPA receptors in the post-synaptic density. This high-precision, 'surgical' tool has found its way into research addressing basic memory questions, such as the involvement of the hippocampus in recognition memory (Hardt et al, 2010, 2010b).
Our analysis raises questions of what constitutes episodic memory and how to effectively study this type of memory in animal models. As noted already, episodic memory is the knowledge for what happened where and when. And in humans, according to one account of episodic memory (Tulving, 1985), the recall of such a memory involves 'autonoetic' awareness, or the sense of a self-experiencing the recall and its presence therein. Whether such 'mental time travel' is accompanied in animals by the same experience of self-awareness is not accessible to neuroscientific investigation; indeed, even in humans the existence of autonoetic awareness cannot be objectively measured owing to its private nature.

Episodic memories capture knowledge about unique events, and hence require a memory system that immediately, in one attempt, encodes automatically, that is, unintentionally, as much as possible of what is perceived. Despite event phenomenology, many paradigms used in human and animal studies relate only nominally to events in real life. In humans, learning of word lists or lists of pictures, usually repeatedly until participants reach a certain criterion, presents a widely used model for episodic memory, and for studies probing recollection/familiaritybased recognition. Usually, participants are aware that their memory for the studied items will be tested subsequently, so they might use encoding strategies that are different from the ones they would engage in real-life situations, where such predictions cannot be made: we all know what we had for breakfast today, but most of us did not have the intention to remember it later.

Attempts to translate these and similar human paradigms into animal models face the same problem. For example, Fortin et al (2004) describe an ingenious study in which rats' ability to form olfactory memories is exploited in an odor-recognition paradigm that follows the structure of human experiments assessing recollection- and familiaritybased memory. Food-deprived rats were first extensively trained in the somewhat complex experimental procedure (of the type non-matching to sample), which required the animals to first sample a set of 10 individually presented odors, which came in the form of scented playground sand deposited in small cups. After a 30-min delay, their odor memory was tested by sequentially presenting 20 cups, with 10 cups containing old and 10 cups containing novel odors. If the test odor was new, rats were required to dig for a food reward in the test cup. If it was old, they were to abstain from digging in the test cup for the reward, but instead had to approach a cup at the opposite end of the cage in which they were tested to obtain a reward.

Thus, rats could make two types of choices. They could produce 'hits', when they either correctly dug for the reward in the test cup in case the test odor was new or when they instead approached the cup at the opposite end when the test odor was old. They could produce 'false alarms' when they dug for the reward in case the odor was old or approached the empty cup at the back of the cage when the odor was new. In addition, Fortin et al biased the rats' 
response criterion by varying the height of the test cup (which varied the effort involved in digging for the food reward) and simultaneously providing a small or large reward, respectively, at the end of the cage (the response criterion thus varies from conservative - low cup and small reward - to liberal-deep cup and large reward). As in human studies, they used ROC (receiver operating characteristics) analyses to determine whether rats used familiarity- and recollection-based recognition processes. They found that normal rats, like humans, have asymmetric curvilinear ROC curves (indicating use of both familiarityand recollection-based processing). And, like humans with hippocampal damage, rats that received bilateral lesions to dorsal and ventral aspects of the hippocampus produced symmetric curvilinear ROC curves, indicating that their recognition performance was based on familiarity processing alone.

This powerful paradigm has been successfully used to study the involvement of the prefrontal cortex as well as the effects of aging on recognition memory in rats (Eichenbaum et al, 2009). Although it implements all the features of human studies that use the recollection/familiarity distinction, this paradigm seems less well suited to study the what-when-where triad characteristic of episodic memory. However, as the MTL is critically involved in recollection and familiarity, the lack of a 'where' component in this task may not be that important. Indeed, this task may overcome a crucial shortcoming of many other animal models of human episodic memory tasks: recognition performance in humans is usually assessed using stimuli for which memory representations already exist. For example, humans understand the meaning of the words presented on word lists, and they can readily identify the objects presented on pictures. Thus, they have pre-existing conceptual or schematic knowledge that will permit more rapid encoding. Rats normally do not have this advantage. One can view the extensive training in tasks, such as the one used by Eichenbaum and co-workers as allowing rats to acquire schematic knowledge, which then allows them to recruit memory processes similar to humans.

Support for the benefit of schematic or conceptual knowledge for efficient encoding, which is required for rapid event-memory formation, comes from human as well as rat studies. In humans, we have shown that the rapid integration of new information into an existing cognitive map, an allocentric spatial representation of an environment that requires the hippocampus, depends on the nature of the novel stimulus - additional cues that predict a target location were incorporated into an existing cognitive map only when they showed concrete objects (eg, boat, apple, etc), but not when they depicted abstract objects (Chinese logographs for the concrete images) (Hardt and Nadel, 2009). Our results suggest that rapid acquisition depends on the ease with which a cue can be encoded - the existence of schematic knowledge permits quick conceptual coding. When this is not available, a large number of perceptual elements of several cues need to be quickly encoded and then remembered in order to permit object discrimination. Such elaborate coding might not be available for all objects present in a certain event, which may explain the ease with which perceptual details of episodic memories can be manipulated (eg, Loftus et al, 1978).

As mentioned above, laboratory animals usually do not possess schematic knowledge of the experimental apparatus and procedure, and thus often require extensive training. Tse et al (2007) showed that if rats acquired schematic (or conceptual) knowledge, then rapid encoding and consolidation of complex event memory becomes possible. In their paired-associates task (which depended on the hippocampus for acquisition), rats learned to dig for food at specific locations in an open-field 'event' arena. Animals were cued with a specific flavor at a start box (eg, bacon), and could then find more of this food at a specific location in the arena. Six flavor-location pairs were used, and the spatial arrangement of these pairs in the event arena constituted the schematic knowledge rats acquired. After such a location schema was acquired over several training sessions, two new flavor-location pairs were presented in schema-consistent locations for only two sessions. Probe tests showed that only two training sessions sufficed to acquire these new pairs. However, when rats were first trained by regularly changing the food-flavor locations, such that a consistent schema could not be acquired, rats were not able to acquire two new flavor-place associations within two sessions. These results indicate that available conceptual knowledge can facilitate rapid acquisition of event-like knowledge in rats.

Although the animal studies described above provide novel and important insights into event-like memoryprocessing capabilities of animals, paradigms that require extensive training might not be ideal models for capturing the essence of human episodic memory. Some have argued that it might be more adequate to develop paradigms that make use of rats' natural tendency to preferentially explore novel over familiar stimuli (eg, Dere et al, 2006; Eacott and Easton, 2010). One advantage of this approach is that it requires little to no pre-training, as rats readily express this behavior, and form complex memories of what they encountered, when, and where - that is, they automatically and rapidly form event-like memories.

We described above in detail a recently developed novelty-preference-based paradigm (Easton and Eacott, 2009; see also Eacott et al, 2005 for an earlier, slightly different version of the task). Using a similar approach, Kart-Teke et al (2006) employed a simpler apparatus (square open field), commonly used in object recognition studies (eg, Ennaceur and Delacour, 1988; Mumby et al, 2002; Figure 4c). After habituating the rats to the open-field apparatus for 3 days, rats received two 5-min sampling trials, and then a 5-min probe trial (the trials were all $50 \mathrm{~min}$ apart from each other). In the first sampling trial, four identical copies of the same object (A) were present at positions $1,2,3$, and 4 . In the second sampling trial, four identical copies of a different object (B) were displayed, 
such that two of them were at the same location as two objects of the first phase (ie, 1,2), and two were at novel positions (ie, 5, 6). In the probe trial, rats encountered two objects from the first sampling phase (A1, A2), and two objects from the second sampling phase (B1, B2). One object from each phase was at its original position (A1 at position 1 , and $\mathrm{B} 1$ at position 5), one object from the first phase at a position that has been occupied by a B object, and one object $B$ at a position that had been occupied by an A object (B2 at position 4). Thus, during the probe trial, objects varied in their relative familiarity - the $B$ objects were more recent than the A objects, and thus should be less familiar than the A objects. In addition, two objects were at new locations, with the A object at a more recently occupied location than the $\mathrm{B}$ object. If during the probe trial the rats explore the more recently presented (hence more familiar) objects less than the objects presented in the first sampling phase, they would express knowledge for what was presented when. And preferential exploration for the objects at novel locations would indicate knowledge for where. The results confirmed these predictions: rats spent more time exploring the displaced objects, and less time exploring objects presented more recently.

Although established tasks like the Morris watermaze, radial-arm maze, and contextual fear conditioning have provided crucial insights into the functions of the hippocampus and structures of the hippocampal complex, they cannot fully address questions concerned with episodic memory. The novel paradigms we briefly discussed here can serve as examples of how the critical criteria of event or episodic memory can be implemented in simple and efficient protocols. If the research question is concerned with human episodic memory, it seems prudent to employ one these approaches, or to design a novel paradigm that incorporates the critical elements of episodic memory that are accessible to experimental methods. In this context, we note the omission of important contributions by Clayton and Dickinson on episodic-like memory in scrub jays (eg, Clayton and Dickinson, 1998; Clayton et al, 2001, 2003; Raby et al, 2007). This omission reflects the fact that birds are rarely if ever used as model systems in pharmacological research.

\section{FUTURE DIRECTIONS}

How the brain establishes LTM, ie, the processes implementing cellular and systems consolidation, has been the focus of considerable research in recent decades. Thanks to these efforts, some of the complex machinery involved in LTM formation has been unveiled. These insights into memory have led some to conclude, erroneously in our view, that once a memory engram, or representation, overcomes its initial phase of instability (characterized by the retrograde temporal gradient of amnesia), it enters a permanently stable state. And, further, that such permanent memories engage only a small number of brain regions.
Failures of memory were assumed to result from focal brain damage or degenerative brain diseases impacting these 'memory' structures, 'interference' from other memories, or some transient problem with retrieval. The broader conceptualization of memory we favor, in which the focus is on representational systems throughout the brain, suggests questions for future research that might further illuminate memory systems and processes.

First, how does the brain maintain some memories for decades, whereas others are forgotten after days, weeks, months, or a few years? We believe that research leading to an understanding of LTM maintenance and forgetting will ultimately permit therapeutic manipulation of these processes (ie, non-degenerative and pathological forms of decay, and thus also memory persistence). The pioneering research on $\mathrm{PKM} \zeta$ and its role in LTM maintenance represents, in our opinion, a first step in this direction.

Second, a related set of questions concerns LTM dynamics. Wide-spread interest in post-retrieval LTM plasticity (ie, research on the re-consolidation phenomenon) illustrates the recognition in the neurosciences of how use, ie, retrieval, can change both the contents and strength of LTMs. Particularly important will be research programs that study memory in real-life situations in addition to artificial laboratory settings. In the end, memory serves to adapt the organism to an ever-changing environment, and as studies of memory re-activation have shown, this can involve inducing states of plasticity in what were previously thought to be stable LTM representations. The mechanisms that induce plasticity, update some memories, and protect others from modification are still poorly understood. Unraveling these mechanisms has the potential to lead to the development of therapeutic techniques that directly modify memory representations underlying maladaptive behaviors. It is important to note that such techniques will raise serious ethical issues.

Third, researchers using animal models are just beginning to develop paradigms implementing aspects of human memory that reflect the complexity of real-world situations. As these kinds of studies proceed, the preferential use of experimentally naïve animals to maximize stimulus control needs to be reconsidered. Research on 'schematization' in rats illustrates both the challenges and the advantages of making animal-based memory research more relevant to humans, thereby improving its translational value.

\section{CONCLUSION}

A review of recent work on memory systems suggests a reconsideration of the long-held view that the MTL constitutes a system devoted to LTM, but not involved in STM or perception. An approach focused instead on viewing brain systems as concerned with representations of different kinds of knowledge fits the data better. Such an approach allows one to ask and answer traditional questions about memory, and makes suggestions about the kinds of 
paradigms that would be most helpful in future studies using animals to explore memory function and dysfunction.

\section{ACKNOWLEDGEMENTS}

LN was supported by the National Science Foundation and the Down Syndrome Research and Treatment Foundation. $\mathrm{OH}$ was supported by the German Research Foundation (Deutsche Forschungsgemeinschaft, DFG).

\section{DISCLOSURE}

The authors declare no conflict of interest.

\section{REFERENCES}

Addis DR, Moscovitch M, Crawley AP, McAndrews MP (2004). Recollective qualities modulate hippocampal activation during autobiographical memory retrieval. Hippocampus 14: 752-762.

Aggleton JP, Brown MW (1999). Episodic memory, amnesia and the hippocampalanterior thalamic axis. Behav Brain Sci 22: 425-489. This influential paper proposed that recognition memory and recall are subserved by distinct neural systems.

Atkinson RC, Shiffrin RM (1968). Human memory: a proposed system and its control processes. In Spence KW, Spence JT (eds. The Psychology of Learning and Motivation Vol 2. Academic Press: New York. pp 89-195.

Axmacher N, Elger CE, Fell J (2009). Working memory-related hippocampal deactivation interferes with long-term memory formation. J Neurosci 29: 1052-1060.

Baddeley AD (2000). The episodic buffer: A new component of working memory? Trends Cog Scie 4: 417-423.

Baddeley A, Allen R, Vargha-Khadem F (2010). Is the hippocampus necessary for visual and verbal binding in working memory? Neuropsychologia 48: 1089-1095.

Baddeley AD, Hitch GJ (1974). Working memory. In Bower GH (ed), The psychology of learning and motivation Vol. 8. Academic Press: New York.

Barch DM (2006). What can research on schizophrenia tell us about the cognitive neuroscience of working memory? Neuroscience 139: 73-84.

Barense MD, Bussey TJ, Lee ACH, Rogers TT, Davies RR, Saksida LM et al (2005). Functional specialization in the human medial temporal lobe. J Neurosci 25: 10239-10246.

Barense MD, Gaffan D, Graham KS (2007). The medial temporal lobe processes online representations of complex objects. Neuropsychologia 45: 2963-2974.

Barnes CA (1988). Spatial learning and memory processes: the search for their neurobiological mechanisms in the rat. Trends Neurosco 11: 163-169.

Bartlett FC (1932). Remembering. Cambridge University Press: Cambridge. Ahead of his time, Bartlett introduced concepts about memory that have long been embraced by cognitive psychology, but only recently have begun to influence the neuroscientific study of memory. Most notably, Bartlett concluded from experiments on memory for prose material that remembering is a reconstructive process, and hence subject to strong alterations, that typically go unnoticed by the reconstructing individual.

Bayley PJ, Hopkins RO, Squire LR (2003). Successful recollection of remote autobiographical memories by amnesic patients with medial temporal lobe lesions. Neuron 38: 135-144.

Bayley PJ, Squire LR (2002). Medial temporal lobe amnesia: gradual acquisition of factual information by nondeclarative memory. J Neurosci 22: 5741-5748.

Bergman ET, Roediger III HL (1999). Can Bartlett's repeated reproduction experiments be replicated? Mem Cogn 27: 937-947

Bernard FA, Bullmore ET, Graham KS, Thompson SA, Hodges JR, Fletcher PC (2004). The hippocampal region is involved in successful recognition of both remote and recent famous faces. Neurolmage 22: 1704-1717.

Biedenkapp JC, Rudy JW (2007). Context preexposure prevents forgetting of a contextual fear memory: Implication for regional changes in brain activation patterns associated with recent and remote memory tests. Learn Mem 14: 200-203.

Bird CM, Burgess N (2008). The hippocampus and memory: insights from spatial processing. Nat Rev Neurosci 9: 182-194.

Brown JA (1958). Some tests of the decay theory of immediate memory. Q J Exp Psych 10: 12-21.

Brown MW, Aggleton JP (2001). Recognition memory: what are the roles of the perirhinal cortex and hippocampus? Nat Rev Neurosci 2: 51-61.
Brunet A, Orr SP, Tremblay J, Robertson K, Nader K, Pitman RK (2008). Effect of post-retrieval propranolol on psychophysiologic responding during subsequent script-driven traumatic imagery in post-traumatic stress disorder. J Psychiatr Res 42: 503-506. (E-pub ahead of print 22 June 2007)

Buckley MJ, Gaffan D (2006). Perirhinal cortical contributions to object perception. Trends Cogn Sci 10: 100-107.

Buckner $\mathrm{RL}$ (2010). The role of the hippocampus in prediction and imagination. Annu Rev Psychol 61: 27-48. An excellent review of the role of the hippocampus is thinking about the future, and the relation between such future thinking and remembering the past

Buckner RL, Wheeler ME, Sheridan MA (2001). Encoding processes during retrieval tasks. J Cogn Neurosci 13: 406-415.

Bussey TJ, Saksida LM (2007). Memory, perception and the ventral visual perirhinal-hippocampal stream: thinking outside the boxes. Hippocampus 17: 898-908.

Bussey TJ, Saksida LM, Murray EA (2003). Impairments in visual discrimination after perirhinal cortex lesions: testing 'declarative' vs. 'perceptual-mnemonic' views of perirhinal cortex function. Eur J Neurosci 17: 649-660.

Canal CE, Chang Q, Gold PE (2007). Amnesia produced by altered release of neurotransmitters after intraamygdala injections of a protein synthesis inhibitor. Proc Natl Acad Sci USA 104: 12500-12505.

Cashdollar N, Malecki U, Rugg-Gunn FJ, Duncan JS, Lavie N, Duzel E (2009). Hippocampus-dependent and -independent theta-networks of active maintenance. Proc Natl Acad Sci USA 106: 20493-20498.

Cermak S (1984). The episodic/semantic distinction in amnesia. In Squire LR, Butters N (ed), The Neuropsychology of Memory. The Guildford Press: New York.

Chadwick MJ, Hassabis D, Weiskopf N, Maguire EA (2010). Decoding individual episodic memory traces in the human hippocampus. Curr Biol 20: 1-4.

Chan JSK, Thomas AK, Bulevich JB (2009). Recalling a witnessed event increases eyewitness suggestibility: the reversed testing effect. Psychol Sci 20: $66-73$

Cipolotti L, Shallice T, Chan D, Fox N, Scahill R, Harrison G et al (2001). Long-term retrograde amnesia... the crucial role of the hippocampus. Neuropsychologia 39: 151-172

Clark RE, Broadbent NJ, Squire LR (2005a). Hippocampus and remote spatial memory in rats. Hippocampus 15: 260-272.

Clark RE, Broadbent NJ, Squire LR (2005b). Impaired remote spatial memory after hippocampal lesions despite extensive training beginning early in life. Hippocampus 15: 340-346. Definitive studies of remote spatial memory in the rat, showing that the hippocampus is always essential to the expression of such memories.

Clayton NS, Bussey TJ, Dickinson A (2003). Can animals recall the past and plan for the future? Nat Rev Neurosci 4: 685-691.

Clayton NS, Dickinson A (1998). Episodic-like memory during cache recovery by Scrub-jays. Nature 395: 272-274

Clayton NS, Yu KS, Dickinson A (2001). Scrub-jays (Aphelocoma coerulescens) form integrated memories of the multiple features of caching episodes. J Exp Psychol: Anim Behav Process 27: 17-29.

Cohen NJ, Eichenbaum H (1993). Memory, Amnesia and the Hippocampal System. MIT Press: Cambridge, MA.

Cohn M, Moscovitch M, Lahat A, McAndrews MP (2009). Recollection versus strength as the primary determinant of hippocampal engagement at retrieval. Proc Natl Acad Sci USA 106: 22451-22455.

Colgin LL, Denninger T, Fyhn M, Hafting T, Bonnevie T, Jensen O et al (2009). Frequency of gamma oscillations routes flow of information in the hippocampus. Nature 462: 353-357.

Conway MA, Turk DJ, Miller SL, Logan J, Nebes RD, Meltzer CC et al (1999). A positron emission tomography (PET) study of autobiographical memory retrieval. Memory 7: 679-702.

Corkin S (1968). Acquisition of motor skill after bilateral medial temporal-lobe excision. Neuropsychologia 6: 255-265.

Daniel TC (1972). Nature of the effect of verbal labels on recognition memory for form. Exp Psychol 96: 152-157.

Danker JF, Anderson JR (2010). The ghosts of brain states past: remembering reactivates the brain regions engaged during encoding. Psychol Bull 136: 87-102. Summarizing the available evidence, this review shows that the brain areas involved in encoding memory are also involved in retrieving it. The conclusions and implications of this paper are fundamental for theories of memory organization.

Davachi L, Mitchell JP, Wagner AD (2003). Multiple routes to memory: distinct medial temporal lobe processes build item and source memories. Proc Natl Acad Sci USA 100: 2157-2162.

Debiec J, LeDoux JE, Nader K (2002). Cellular and systems reconsolidation in the hippocampus. Neuron 36: 527-538. 
Dere E, Kart-Teke E, Huston JP, De Souza Silva MA (2006). The case for episodic memory in animals. Neurosci Biobehav Rev 30: 1206-1224.

Diekelmann S, Wilhelm I, Born J (2009). The whats and whens of sleep-dependent memory consolidation. Sleep Med Rev 13: 309-321.

Dougal S, Phelps EA, Davachi L (2007). The role of medial temporal lobe in item recognition and source memory for emotional stimuli. Cogn Affect Behav Neurosci 7: 233-242.

Douville K, Woodard JL, Seidenberg M, Miller SK, Leveroni CL, Nielson KA et al (2005). Medial temporal lobe activity for recognition of recent and remote famous names: an event-related fMRI study. Neuropsychologia 43: 693-703.

Dragoi G, Buszáki G (2006). Temporal encoding of place sequences by hippocampal cell assemblies. Neuron 50: 145-157.

Eacott MJ, Easton A (2010). Episodic memory in animals: remembering which occasion. Neuropsychologia 48: 2273-2280.

Eacott MJ, Easton A, Zinkivskay A (2005). Recollection in an episodic-like memory task in the rat. Learn Mem 12: 221-223.

Easton A, Eacott MJ (2009). Recollection of episodic memory within the medial temporal lobe: behavioural dissociations from other types of memory. Behav Brain Res (doi:10.1016/j.bbr.2009.10.019).

Ebbinghaus H (1885/1913). Memory: A Contribution to Experimental Psychology. Teachers College, Columbia University: New York.

Eichenbaum H, Fortin N, Sauvage M, Robitsek RJ, Farovik A (2010). An animal model of amnesia that uses Receiver Operating Characteristics (ROC) analysis to distinguish recollection from familiarity deficits in recognition memory. Neuropsychologia 48: 2281-2289.

Eichenbaum H, Yonelinas AP, Ranganath C (2007). The medical temporal lobe and recognition memory. Annu Rev Neurosci 30: 123-152.

Ennaceur A, Delacour J (1988). A new one-trial test for neurobiological studies of memory in rats. 1: Behavioral data. Behav Brain Res 31: 47-59.

Felleman DJ, Van Essen DC (1991). Distributed hierarchical processing in the primate cerebral cortex. Cereb Cortex 1: 1-47.

Fletcher PC, Frith CD (2009). Perceiving is believing: a Bayesian approach to explaining the positive symptoms of schizophrenia. Nat Rev Neurosci 10: 48-58.

Forcato C, Argibay PF, Pedreira ME, Maldonado H (2009). Human reconsolidation does not always occur when a memory is retrieved: the relevance of the reminder structure. Neurobiol Learn Mem 91: 50-57.

Forcato C, Burgos VL, Argibay PF, Molina VA, Pedreira ME, Maldonado H (2007). Reconsolidation of declarative memory in humans. Learn Mem 14: 295-303.

Forcato C, Rodríguez MLC, Pedreira ME, Maldonado H (2010). Reconsolidation in humans opens up declarative memory to the entrance of new information. Neurobiol Learn Mem 93: 77-84.

Fortin NJ, Wright SP, Eichenbaum H (2004). Recollection-like memory retrieval in rats is dependent on the hippocampus. Nature 431: 188-191.

Gaffan D (1974). Recognition impaired and association intact in the memory of monkeys after transection of the fornix. J Comp Physiol Psychol 86: 1100-1109. One of the first articles suggesting that there are multiple memory systems, of which the hippocampus is but one. Also describes a paradigmmatching to sample - that subsequently was used as a signature task for assessing declarative memory.

Galluccio L (2005). Updating reactivated memories in infancy: I. Passive- and active-exposure effects. Dev Psychobiol 47: 1-17.

Galluccio L, Rovee-Collier C (2005). Updating reactivated memories in infancy: II. Time passage and repetition effects. Dev Psychobiol 47: 18-30.

Gauld A, Stephenson GM (1967). Some experiments related to Bartlett's theory of remembering. Br J Psychol 58: 39-49.

Gelbard-Sagiv H, Mukamel R, Harel M, Malach R, Fried I (2008). Internally generated reactivation of single neurons in human hippocampus during free recall. Science 322: 96-101.

Gibbs BR, Rude SS (2004). Overgeneral autobiographical memory as depression vulnerability. Cogn Ther Res 28: 511-526.

Gillboa A, Winocur G, Grady CL, Hevenor SJ, Moscovitch M (2004). Remembering our past: functional neuroanatomy of recollection of recent and very remote personal events. Cereb Cortex 14: 1214-1225.

Giovanello KS, Verfaellie M, Keane MM (2003). Disproportionate deficit in associative recognition relative to item recognition in global amnesia. Cogn Affect Behav Neurosci 3: 186-194.

Goodrich-Hunsaker NJ, Hopkins RO (2009). Word memory test performance in amnesic patients with hippocampal damage. Neuropsychology 23: 529-534.

Graham KS, Barense MD, Lee ACH (2010). Going beyond LTM in the MTL: a synthesis of neuropsychological and neuroimaging findings on the role of the medial temporal lobe in memory and perception. Neuropsychologia 48: 831-853. Excellent review of the evidence showing that one cannot draw a sharp line between perception and memory in the brain. The medial temporal lobe is implicated in both.
Guderian S, Schott BH, Richardson-Klavehn A, Duzel E (2009). Medial temporal theta state before an event predicts episodic encoding success in humans. Proc Natl Acad Sci USA 106: 5365-5370.

Haist F, Gore JB, Mao H (2001). Consolidation of human memory over decades revealed by functional magnetic resonance imaging. Nat Neurosci 4: 11391145.

Halgren E, Wilson CL, Stapleton JM (1985). Human medial temporal-lobe stimulation disrupts both formation and retrieval of recent memories. Brain and Cognition 4: 287-295.

Hannula DE, Ranganath C (2008). Medial temporal lobe activity predicts successful relational memory binding. Journal of Neuroscience 28: 116-124.

Hannula DE, Tranel D, Cohen NJ (2006). The long and the short of it: relational memory impairments in amnesia, even at short lags. Journal of Neuroscience 26: 8352-8359.

Hardt O, Einarsson EÖ, Nader K (2010a). A bridge over troubled water: Reconsolidation as a Link Between Cognitive and Neuroscientific Memory Research Traditions. Annual Review of Psychology 61: 141-167.

Hardt O, Migues PV, Hastings M, Wong J, Nader K (2010b). PKM 1-day- and 6-day-old long-term object location but not object identity memory in dorsal hippocampus. Hippocampus 20: 691-695.

Hardt O, Nadel L (2009). Cognitive maps and attention. Progr Brain Res 176: 181-194.

Hardt O, Wang S-H, Nader K (2010). Storage or retrieval deficit: the yin and yang of amnesia. Learn Mem 16: 224-230. This paper introduces the first unambiguous method to study the yet unresolved question whether experimentally induced amnesia reflects a retrieval or a storage impairment, that is, whether the amnesia reflects a possibly transient problem in recalling memory or the actual permanent loss of memory. Importantly, this method can be used to determine the fate of memory in many situations in which it is no longer expressed.

Hartley T, Bird CM, Chan D, Cipolotti L, Husain M, Vargha-Khadem F et al (2007). The hippocampus is required for short-term topographical memory in humans. Hippocampus 17: 34-48.

Harvey CD, Collman F, Dombeck DA, Tank DW (2009). Intracellular dynamics of hippocampal place cells during virtual navigation. Nature 461: 941-946.

Hebb DO (1949). The Organization of Behavior. Wiley-Interscience: New York (A seminal work linking the brain and cognitive functions, still worth a careful reading today.

Henke K (2010). A model for memory systems based on processing modes rather than consciousness. Nature Reviews Neuroscience 11: 523-532.

Hirsh R (1974). The hippocampus and contextual retrieval of information from memory: a theory. Behav Biol 12: 421-444. An early proponent of multiple memory systems, in this case described as 'on-line' vs 'off-line', or 'context-sensitive' vs 'context-insensitive'.

Holdstock JS, Mayes AR, Gong QY, Roberts N, Kapur N (2005). Item recognition is less impaired than recall and associative recognition in a patient with selective hippocampal damage. Hippocampus 15: 203-215. One of the early studies showing that hippocampal damage differentially impacts recognition and recollection.

Honig WK (1978). Studies of working memory in the pigeon. In: Hulse SH, Fowler H, Honig WK (eds.Cognitive Processes in Animal Behavior. Lawrence Erlbaum Associates: Hillsdale, NJ.

Hoscheidt SM, Nadel L, Payne J, Ryan L (2010). Hippocampal activation during retrieval of spatial context from episodic and semantic memory. Behav Brain Res 212: 121-132.

Hupbach A, Gomez R, Nadel L (2009). Episodic memory reconsolidation: updating or source confusion? Memory 17: 502-510.

Hupbach A, Gomez R, Nadel L, Hardt O (2007). Reconsolidation of episodic memories: a subtle reminder triggers integration of new information. Learn Mem 14: $47-53$.

Hupbach A, Hardt O, Gomez R, Nadel L (2008). The dynamics of memory: contextdependent updating. Learn Mem 15: 574-579. This paper shows that in humans re-consolidation of episodic memory requires reinstatement of the original learning context, that is, the spatial location in which memory was originally acquired.

Jacobs WJ, Nadel L (1985). Stress-induced recovery of fears and phobias. Psychol Rev 92: 512-531.

James W (1890). The Principles of Psychology. Henry Holt and Company: New York.

Jarrard JE (1978). Selective hippocampal lesions: differential effects on performance by rats of a spatial task with preoperative versus postoperative training. J Comp Phychol 92: 1119-1127.

Johnson A, Redish DA (2007). Neural ensembles in CA3 transiently encode paths forward of the animal at a decision point. J Neurosci 27: 12176-12189. The authors show that place field activity in rat precedes the actual movement 
when the animal has to make a decision at a junction. The data reported suggest that the animal 'simulates' moving into directions, which could reflect place field activity driven by replaying previous experiences in order to make decisions.

Kart-Teke E, De Souza Silva MA, Huston JP, Dere E (2006). Wistar rats show episodiclike memory for unique experiences. Neurobiol Learn Mem 85: 173-182.

Kindt M, Soeter M, Vervliet B (2009). Beyond extinction: erasing human fear responses and preventing the return of fear. Nat Neurosci 12: 256-258. This well-controlled study shows that in humans fear responses can be successfully abolished combining memory re-activation with administration of the beta-adrenergic antagonist propranolol, and that the loss of the fear response is long lasting

Kinsbourne M, Wood F (1975). Short-term memory and the amnesic syndrome. In: Deutsch D, Deutsch JA (eds.Short Term Memory. Academic Press: New York. pp 257-291.

Konkel A, Cohen N (2009). Relational memory and the hippocampus: representations and methods. Front Neurosci 3: 166-174.

Kirwan CB, Stark CE (2004). Medial temporal lobe activation during encoding and retrieval of novel face-name pairs. Hippocampus 14: 919-930.

Kraus MS, Keefe RS, Krishnan RK (2009). Memory-prediction errors and their consequences in schizophrenia. Neuropsychol Rev 19: 336-352.

Kristo G, Janssen SMJ, Murre JMJ (2009). Retention of autobiographical memories: an Internet-based diary study. Memory 17: 816-829.

Kroll NE, Knight RT, Metcalfe J, Wolf ES, Tulving E (1996). Cohesion failure as a source of memory illusions. J Mem Lang 35: 176-196.

Kumaran D, Maguire EA (2005). The human hippocampus: cognitive maps or relational memory? J Neurosci 25: 7254-7259.

Kumaran D, Maguire EA (2009). Novelty signals: a window into hippocampal information processing. Trends Cogn Sci 13: 47-54.

Lechner HA, Squire LR, Byrne JH (1999). 100 years of consolidation-remembering Muller and Pilzecker. Learn Mem 6: 77-87.

Lee $\mathrm{ACH}$, Rudebeck SR (2010). Human medial temporal lobe damage can disrupt the perception of single objects. J Neurosci 30: 6588-6594. Recent demonstration that medial temporal lobe structures can be critical for perception, even when memory demands are carefully controlled.

Lehmann H, Lacanilao S, Sutherland RJ (2007). Complete or partial hippocampal damage produces equivalent retrograde amnesia for remote contextual fear memories. Eur J Neurosci 25: 1278-1286.

Levy DA, Shrager Y, Squire LR (2005). Intact visual discrimination of complex and feature-ambiguous stimuli in the absence of perirhinal cortex. Learn Mem 12: 61-66.

Lewis DJ (1979). Psychobiology of active and inactive memory. Psychol Bull 86: 1054-1083. Based on his findings that long-term memory re-enters a state of plasticity similar in vulnerability to newly acquired memory, Lewis proposed the first theoretical framework to explain these findings. Largely and unduly ignored by mainstream psychology, Lewis argued that memory can reside in two states, active and inactive, and that only when in the active state - which it enters during use - is memory open to alterations.

Lewis DJ, Misanin JR, Miller RR (1968). The recovery of memory following amnestic treatment. Nature 220: 704-705.

Ling DSF, Benardo LS, Serrano PA, Blace N, Kelly MT, Crary JF et al (2002). Protein kinase Mzeta is necessary and sufficient for LTP maintenance. Nat Neurosci $\mathbf{5}$ : 295-296.

Loftus EF, Miller DG, Burns HJ (1978). Semantic integration of verbal information into a visual memory. J Exp Psychol Hum Learn Mem 4: 19-31.

Maguire EA, Frith CD (2003). Lateral asymmetry in the hippocampal response to the remoteness of autobiographical memories. J Neurosci 23: 5302-5307.

Maguire EA, Henson R, Mummery CJ, Frith CD (2001). Activity in prefrontal cortex, not hippocampus, varies parametrically with the increasing remoteness of memories. Neuroreport 12: 441-444.

Marr D (1971). Simple memory: a theory for archicortex. Philos TransRoy Soc Lond Ser B 262: 23-81. Marr produced three papers of fundamental theoretical relevance for current conceptualizations of brain function and organization. In this article, Marr proposed specific functions for some brain areas based on biological constraints. Marr assumed that memory is coded sparsely, that the hippocampal role in memory is temporary, and that the hippocampus provides a content-addressable system capable of pattern completion.

McClelland JL, McNaughton BL, O'Reilly RC (1995). Why there are complementary learning systems in the hippocampus and neocortex: insights from the successes and failures of connectionist models of learning and memory. Psychol Rev 102: 419-457. According to the influential connectionist, Marr-inspired, memory model proposed in this paper, the hippocampus and the neocortex have different roles in memory. The rapid-learning hippocampus quickly acquires new memory content and then 'teaches' it to the slow-learning neocortex by replaying the content during off-line intervals (eg, sleep) or during active rehearsal.

Migues PV, Hardt O, Wu DC, Gamache K, Sacktor TC, Wang YT et al (2010). PKMzeta maintains memories by regulating GluR2-dependent AMPA receptor trafficking. Nat Neurosci 13: 630-634.

Milner B (1966). Amnesia following operation on the temporal lobes. In: Whitty CWM, Zangwill OL (eds.Amnesia. London: Butterworths. pp 109-133.

Misanin JR, Miller RR, Lewis DJ (1968). Retrograde amnesia produced by electroconvulsive shock after reactivation of consolidated memory trace. Science 160: 554-555. The first report of the memory re-consolidation effect, although the authors did not name it as such. This paper showed that consolidation does not permanently abolish plasticity, but that consolidated memory can be impaired provided it is re-activated before the application of the amnesic treatment. This anomaly within the then widely accepted consolidation framework provoked a swift negative reaction from the establishment, and was largely ignored in the decades that followed

Montgomery SM, Buzsáki G (2007). Gamma oscillations dynamically couple hippocampal CA3 and CA1 regions during memory task performance. Proc Natl Acad Sci USA 104: 14495-14500.

Morris RG (2001). Episodic-like memory in animals: psychological criteria, neural mechanisms and the value of episodic-like tasks to investigate animal models of neurodegenerative disease. Philos Trans Roy Soc Lond Ser B 356: 1453-1465.

Müller GE, Pilzecker A (1900). Experimentelle Beitrage zur Lehre von Gedachtnis. Z Psychol 1: 1-300. Using the then standard method of nonsense-syllable learning, the authors of this seminal work concluded from their findings that newly acquired memory remains vulnerable to disruption for some time following acquisition. To explain these observations, they introduced the perseveration-consolidation hypothesis, stating that in order to become consolidated, new memory contents needs to perseverate for some time after learning. Disrupting perseveration impairs consolidation and thus memory retention.

Mumby DG, Gaskin S, Glenn MJ, Schramek TE, Lehmann H (2002). Hippocampal damage and exploratory preferences in rats: memory for objects, places, and contexts. Learn Mem 9: 49-57.

Murray EA, Saksida LM, Bussey TJ (2007). Visual perception and memory: a new view of medial temporal lobe function in primates and rodents. Annu Rev Neurosci 30: 99-122

Nadel L (2008). Multiple memory systems: a new view. In: Roediger III HL, Byrne J (eds.Cognitive Psychology of Memory Vol [1] of Learning and Memory: A Comprehensive Reference. Vol 4. Elsevier: Oxford. pp 41-52.

Nadel L, MacDonald L (1980). Hippocampus: cognitive map or working memory? Behav Neural Biol 29: 405-409.

Nadel L, Moscovitch M (1997). Memory consolidation, retrograde amnesia, and the hippocampal complex. Curr Opin Neurobiol 7: 217-227. The authors propose multiple trace theory as an alternative model of systems consolidation. In contrast to the standard model of systems consolidation, they argue not only that the hippocampus remains critically involved in very remote episodic memories, but that over time its involvement increases as the hippocampal trace expands with each memory re-activation.

Nadel L, Moscovitch M (1998). Hippocampal contributions to cortical plasticity. Neuropharmacology 37: 431-439.

Nadel L, O'Keefe J (1974). The hippocampus in pieces and patches: an essay on modes of explanation in physiological psychology. In: Bellairs R, Gray EG (eds.Essays on the Nervous System, A Festschrift for Prof JZ Young, Clarendon Press: Oxford. pp 367-390. One of the three articles published in 1974 that postulated the existence of multiple memory systems, in this case suggesting that the hippocampus was critical only for place learning in rats. The first explication of what became the 'cognitive map' theory of hippocampal function.

Nadel L, Samsonovich A, Ryan L, Moscovitch M (2000). Multiple trace theory of human memory: computational, neuroimaging, and neuropsychological results. Hippocampus 10: 352-368.

Nader K, Hardt O (2009). A single standard for memory: the case for reconsolidation. Nat Rev Neurosci 10: 224-234. A decade after the resurfacing of the reconsolidation effect into mainstream neuroscience, this review summarizes the large body of findings and critically reviews explanations of post-retrieval memory plasticity alternative to the assumption of a re-consolidation process, concluding that if one accepts the idea of a consolidation process, one must also accept the notion of re-consolidation, as both explanations are based on the same types of evidence.

Nader K, Schafe GE, LeDoux JE (2000). Fear memories require protein synthesis in the amygdala for reconsolidation after retrieval. Nature 406: 722-726.

Nichols EA, Kao YC, Verfaellie M, Gabrieli JD (2006). Working memory and longterm memory for faces: Evidence from $\mathrm{fMRI}$ and global amnesia for involvement of the medial temporal lobes. Hippocampus 19: 604-616. 
O'Keefe J, Nadel L (1978). The Hippocampus as a Cognitive Map. Clarendon Press: Oxford (The formal statement of cognitive map theory, including extensive reviews of the literature to that time. Available for free download at www.cognitivemap.net.

Olson IR, Moore KS, Stark M, Chatterjee A (2006a). Visual working memory is impaired when the medial temporal lobe is damaged. J Cogn Neurosci 18: 1087-1097.

Olson IR, Page K, Moore KS, Chatterjee A, Verfaellie M (2006b). Working memory for conjunctions relies on the medial temporal lobe. J Neurosci 26: 4596-4601.

Olton DS, Becker JT, Handelman GE (1979). Hippocampus, space and memory. Behav Brain Sci 2: 313-322.

Orbach J, Milner B, Rasmussen T (1960). Learning and retention in monkeys after amygdala-hippocampus resection. Arch Neurol 3: 230-251.

Parvez S, Ramachandran B, Frey JU (2010). Functional differences between and across different regions of the apical branch of hippocampal CA1 dendrites with respect to long-term depression induction and synaptic cross-tagging. J Neurosci 30: 5118-5123.

Pastalkova E, Serrano P, Pinkhasova D, Wallace E, Fenton AA, Sacktor TC (2006). Storage of spatial information by the maintenance mechanism of LTP. Science 313: 1141-1144. The authors show in vivo that transiently disrupting activity of the atypical protein kinase $\mathrm{C}$ isoform $\mathrm{M}$ zeta (PKM abolishes established LTP in vivo. They also show that spatial knowledge acquired in a place avoidance task requires uninterrupted PKM $\zeta$ activity for long-term persistence.

Piefke M, Weiss PH, Zilles K, Markowitsch HJ, Fink GR (2003). Differential remoteness and emotional tone modulate the neural correlates of autobiographical memory. Brain 126: 650-668.

Piolino P, Giffard-Quillon G, Desgranges B, Chetelat G, Baron J-C, Eustache F (2004). Re-experiencing old memories via hippocampus: a PET study of autobiographical memory. Neurolmage 22: 1371-1383.

Poreh A, Winocur G, Moscovitch M, Backon M, Goshen E, Ram Z et al (2006). Anterograde and retrograde amnesia in a person with bilateral fornix lesions following removal of a colloid cyst. Neuropsychologia 44: 2241-2248.

Peterson MA (1994). Object recognition processes can and do operate before figure-ground organization. Curr Direct Psychol Sci 3: 105-111. An early discussion of data showing that even fundamental perceptual processes are subject to influences from memory.

Peterson MA, Gibson BS (1994). Must figure-ground organization precede object recognition? An assumption in peril. Psychol Sci 5: 253-259.

Peterson LR, Peterson MJ (1959). Short-term retention of individuatl iterms. J Exp Psych 58L: 193-198.

Peterson MA, Skow E (2008). Suppression of shape properties on the ground side of an edge: evidence for a competitive model of figure assignment. J Exp Psychol Hum Percept Perform 34: 251-267.

Przybyslawski J, Sara SJ (1997). Reconsolidation of memory after its reactivation. Behav Brain Res 84: 241-246.

Qin S, Rijpkema M, Tendolkar I, Piekema C, Hermans EJ, Binder M et al (2009). Dissecting medial temporal lobe contributions to item and associative memory formation. Neurolmage 46: 874-881.

Raby CR, Alexis DM, Dickinson A, Clayton NS (2007). Planning for the future by western-scrub jays. Nature 445: 919-921.

Ranganath C (2010). Binding items and contexts: the cognitive neuroscience of episodic memory. Curr Direct Psychol Sci 19: 131-137.

Ranganath C, Cohen MX, Brozinsky CJ (2005). Working memory maintenance contributions to long-term memory formation: neural and behavioral evidence. J Cogn Neurosci 17: 994-1010.

Ranganath C, D'Esposito M (2001). Medial temporal lobe activity associated with active maintenance of novel information. Neuron 31: 865-873. One of the earliest papers to show a role for hippocampus in short-term memory.

Ribot TH (1881/1887). Les Maladies de la mémoire (Diseases of Memory: An Essay in the Positive Psychology). Appleton and Company: New York.

Roberts WA, Smythe WE (1979). Memory for lists of spatial events in the rat. Learn Motiv 10: 313-336.

Roediger HL, Jacoby JD, McDermott KB (1996). Misinformation effects in recall: creating false memories through repeated retrieval. J Mem Lang 35: 300-318.

Rosenbaum RS, Moscovitch M, Foster JK, Schnyer DM, Gao F, Kovacevic N et al (2008). Patterns of autobiographical memory loss in medial-temporal lobe amnesic patients. J Cogn Neurosci 20: 1490-1506.

Rosenbaum RS, Priselac S, Kohler S, Black SE, Nadel L, Moscovitch M (2000). Studies of remote spatial memory in an amnesic person with extensive bilateral hippocampal lesions. Nat Neurosci 3: 1044-1048.

Roullet P, Sara SJ (1998). Consolidation of memory after its reactivation: involvement of beta noradrenergic receptors in the late phase. Neural Plast 6: 63-68.
Rudoy JD, Voss JL, Westerberg CE, Paller KA (2009). Strengthening individual memories by reactivating them during sleep. Science 326: 1079. Elegant demonstration that re-activation of specific memories during sleep can influence their consolidation.

Russell WR, Nathan PW (1946). Traumatic amnesia. Brain 69: 280-300.

Ryan L, Cox C, Hayes SM, Nadel L (2008). Hippocampal activation during episodic and semantic memory retrieval: comparing category production and category cued recall. Neuropsychologia 46: 2109-2121.

Ryan L, Nadel L, Keil K, Putnam K, Schnyer D, Trouard Tet al (2001). Hippocampal complex and retrieval of recent and very remote autobiographical memories: evidence from functional magnetic resonance imaging in neurologically intact people. Hippocampus 11: 707-714. An early demonstration that retrieving remote, as well as recent, episodic memories activates the hippocampus.

Sacktor TC, Osten P, Valsamis H, Jiang X, Naik MU, Sublette E (1993). Persistent activation of the zeta isoform of protein kinase $\mathrm{C}$ in the maintenance of long-term potentiation. Proc Natl Acad Sci USA 90: 8342-8346.

Saksida LM, Bussey TJ (2010). The representational-hierarchical view of amnesia: translation from animal to human. Neuropsychologia 48: 2370-2384.

Saksida LM, Bussey TJ, Buckmaster CA, Murray EA (2006). No effect of hippocampal lesions on perirhinal cortex-dependent feature-ambiguous visual discriminations. Hippocampus 16: 421-430.

Sara SJ (2000). Retrieval and reconsolidation: toward a neurobiology of remembering. Learn Mem 7: 73-84.

Schacter DL, Addis DR (2009). On the nature of medial temporal lobe contributions to the constructive simulation of future events. Philos Trans Roy Soc Ser B 364: 1245-1253.

Schiller D, Monfils M-H, Raio CM, Johnson DC, LeDoux JE, Phelps EA (2010). Preventing the return of fear in humans using reconsolidation update mechanisms. Nature 463: 49-53.

Schmolck H, Buffalo EA, Squire LR (2000). Memory distortions develop over time: recollections of the O.J. Simpson Trial Verdict after 15 and 32 Months. Psychol Sci 11: 39-45.

Sederberg PB, Kahana MJ, Howard MW, Donner EJ, Madsen JR (2003). Theta and gamma oscillations during encoding predict subsequent recall. J Neurosci 23: 10809-10814.

Shirvalkar PR, Rapp PR, Shapiro ML (2010). Bidirectional changes to hippocampal theta-gamma comodulation predict memory for recent spatial episodes. Proc Natl Acad Sci 107: 7054-7059.

Shrager Y, Gold JJ, Hopkins RO, Squire LR (2006). Intact visual perception in memory-impaired patients with medial temporal lobe lesions. J Neurosci 26 2235-2240.

Shrager Y, Levy DA, Hopkins RO, Squire LR (2008). Working memory and the organization of brain systems. J Neurosci 28: 4818-4822.

Scoville WB, Milner B (1957). Loss of recent memory after bilateral hippocampal lesion. J Neurol Neurosurg Psychiatry 20: 11-21. This classic paper reports psychological profiles of 10 patients, among them HM, who received bilateral medial-temporal lobe resections. The authors conclude that the hippocampus is critically involved in recent memory, but that its role in more remote memory may not be as important, and that this brain region is not fundamental to perception or skill maintenance. Furthermore, the authors relate the extent of hippocampal damage to memory performance, suggesting that the more hippocampal tissue is destroyed, the more severe the memory impairment.

Smith CN, Squire LR (2009). Medial temporal lobe activity during retrieval of semantic memory is related to the age of the memory. J Neurosci 29: 930-938.

Sossin WS (2008). Defining memories by their distinct molecular traces. Trends Neurosci 31: 170-175.

Squire LR (1989). On the course of gorgetting in very long-term memory. J Exp Psychol Learn Mem Cogn 15: 241-245.

Squire LR (1992). Memory and the hippocampus: a synthesis from findings with rats, monkeys and humans. Psychol Rev 99: 195-231.

Squire LR (2009). Memory and brain systems: 1969-2009. J Neurosci 29: $12711-12716$.

Squire LR, Alvarez P (1995). Retrograde amnesia and memory consolidation: a neurobiological perspective. Curr Biol 5: 169-177.

Squire LR, Wixted JT, Clark RE (2007). Recognition memory and the medial temporal lobe: a new perspective. Nat Rev Neurosci 8: 872-883.

Squire LR, Zola-Morgan S (1991). The medial temporal lobe memory system. Science 253: 1380-1386. Clear statement of the influential 'medial temporal lobe memory system hypothesis'.

Staresina BP, Davachi L (2006). Differential encoding mechanisms for subsequent associative recognition and free recall. J Neurosci 26: 9162-9172.

Staresina BP, Davachi L (2008). Selective and shared contributions of the hippocampus and perirhinal cortex to episodic item and associative encoding J Cogn Neurosci 20: 1478-1489. 
Stark CE, Bayley PJ, Squire LR (2002). Recognition memory for single items and for associations is similarly impaired following damage to the hippocampal region. Learn Mem 9: 238-242.

Stark CEL, Squire LR (2003). Hippocampal damage equally impairs memory for single items and memory for conjunctions. Hippocampus 13: 281-292.

Stark CEL, Stark SM, Gordon B (2005). New semantic learning and generalization in an amnesic patient. Neuropsychology 19: 139-151.

Sutherland RJ, O'Brien J, Lehmann $\mathrm{H}$ (2008). Absence of systems consolidation of fear memories after dorsal, ventral, or complete hippocampal damage. Hippocampus 18: 710-718.

Sutin AR, Robins RW (2007). Phenomenology of autobiographical memories: The Memory Experiences Questionnaire. Memory 15: 390-411.

Szpunar KK (2010). Episodic future thought: an emerging concept. Perspect Psychol Sci 5: 142-162.

Teng E, Squire LR (1999). Memory for places learned long ago is intact after hippocampal damage. Nature 400: 675-677.

Teyler TJ, DiScenna P (1986). The hippocampal memory indexing theory. Behav Neurosci 100: 147-154. The authors present an influential theory about hippocampal function, proposing that neocortical modules encode memory contents and that the hippocampus encodes a content-free index pointing to this dispersed activity, which allows for later retrieval.

Tollenaar MS, Elzinga BM, Spinhoven P, Everaerd W (2009). Autobiographical memory after acute stress in healthy young men. Memory 17: 301-310.

Tort AB, Komorowski RW, Manns JR, Kopell NJ, Eichenbaum H (2009). Thetagamma coupling increases during the learning of item-context associations. Proc Natl Acad Sci USA 106: 20942-20947.

Tse D, Langston RF, Kakeyama M, Bethus I, Spooner PA, Patrick A et al (2007). Schemas and memory consolidation. Science 316: 76-82. The authors report findings suggesting that rats can acquire schematic knowledge and that, once established, it greatly improves the speed with which new instances related to this knowledge can be acquired. The data suggest that schemata greatly speed up systems consolidation in the spatial food-foraging task used in these studies: new knowledge becomes independent of the hippocampus in a fraction of the time.

Tulving E (1972). Episodic and semantic memory. In: Tulving E, Donaldson W (eds.Organisation and Memory. Academic Press: New York. pp 382-403.

Tulving E (1983). Elements of Episodic Memory. Oxford University Press: Oxford Tulving discusses several theoretically important conceptualizations in his seminal work that defined a field of scientific investigation of human (and animal) memory and that guide research-either attempts to prove or disprove his ideas - to this day.

Tulving E (1985). Memory and consciousness. Canad Psychologist 25: 1-12.

Tulving E (2002a). Episodic memory: from mind to brain. Annu Rev Psychol 53:
Tulving E (2002b). Chronesthesia: conscious awareness of subjective time. In: Stuss DT, Knight RC (eds.Principles of Frontal Lobe Function. Oxford University Press: New York.

Vann SD, Tsivilis D, Denby CE, Quamme JR, Yonelinas AP, Aggleton JP et al (2009). Impaired recollection but spared familiarity in patients with extended hippocampal system damage revealed by 3 convergent methods. Proc Natl Acad Sci USA 106: 5442-5447.

Viard A, Piolino P, Desgranges B, Chetelat G, Lebreton K, Landeau B et al (2007). Hippocampal activation for autobiographical memories over the entire lifetime in healthy aged subjects: an fMRI study. Cereb Cortex 17: 2453-2467.

Walker MP, Brakefield T, Hobson JA, Stickgold R (2003). Dissociable stages of human memory consolidation and reconsolidation. Nature 425: 616-620.

Wang SH, Teixeira CM, Wheeler AL, Frankland PW (2009). The precision of remote context memories does not require the hippocampus. Nat Neurosci 12: 253-255.

Warrington EK, Weiskrantz $L$ (1968). A study of learning and retention in amnesic patients. Neuropsychologia 6: 283-291. One of the earliest studies showing that amnesics can learn under certain conditions.

Warrington EK, Weiskrantz L (1970). Amnesic syndrome: consolidation or retrieval? Nature 228: 628-630.

Wheeler MA, Roediger III HL (1992). Disparate results of repeated testing: reconciling Ballard's (1913) and Bartlett's (1932) results. Psychol Sci 3: 240-245.

Wills TJ, Lever C, Cacucci F, Burgess N, O'Keefe J (2005). Attractor dynamics in the hippocampal representation of the local environment. Science 30: 873-876.

Wilson MA, McNaughton BL (1994). Reactivation of hippocampal ensemble memories during sleep. Science 265: 676-679.

Wiltgen BJ, Silva AJ (2007). Memory for context becomes less specific with time. Learn Mem 14: 313-317.

Wiltgen BJ, Zhou M, Cai Y, Balaji J, Karlsson MG, Parivash N et al (2010). The hippocampus plays a selective role in the retrieval of detailed contextual memories. Curr Biol 20: 1-9.

Winocur G, Frankland PW, Sekeres M, Fogel S, Moscovitch M (2009). Changes in context-specificity during memory reconsolidation: selective effects of hippocampal lesions. Learn Mem 16: 722-729.

Winocur G, Moscovitch M, Sekeres M (2007). Memory consolidation or transformation: context manipulation and hippocampal representations of memory. Nat Neurosci 10: 555-557.

Wood ER, Dudchenko PA, Robitsek RJ, Eichenbaum H (2000). Hippocampal neurons encode information about different types of memory episodes occurring in the same location. Neuron 27: 623-633.

Wynn VE, Logie RH (1998). The veracity of long-term memories: did Bartlett get it right? Appl Cogn Psychol 12: 1-20.

Zhao L-Y, Zhang X-L, Shi J, Epstein DH, Lu L (2009). Psychosocial stress after reactivation of drug related memory impairs later recall in abstinent heroin addicts. Psychopharmacology 203: 599-608. 